\title{
Status, rivalry and admiration-seeking in narcissism and depression: a behavioral study
}

Anna Szücs ${ }^{1,2}$, Katalin Szanto ${ }^{1}$, Jade Adalbert ${ }^{3}$, Aidan G.C. Wright ${ }^{4}$, Luke Clark $^{3}$, Alexandre Y. Dombrovski ${ }^{*}$

${ }^{1}$ Dept. of Psychiatry, University of Pittsburgh, Pittsburgh

${ }^{2}$ Dept. of Psychiatry, University of Geneva, Geneva, Switzerland

${ }^{3}$ Dept. of Psychology, University of British Columbia, Canada

${ }^{4}$ Dept. of Psychology, University of Pittsburgh, Pittsburgh, USA

* Corresponding author: Alexandre Y. Dombrovski, dombrovskia@gmail.com 


\section{Abstract}

Humans seek admiration to boost their social rank and engage in rivalry to protect it when fearing defeat. Traits such as narcissism and affective states such as depression are thought to influence perception of rank and motivation for dominance in opposite ways, but evidence of the underlying behavioral mechanisms is scant. We investigated the effects of trait dominance, dimensionally-assessed narcissism, and depression on behavioral responses to social defeat in a rigged video game tournament designed to elicit rivalry (stealing points from opponents) and admiration-seeking (paying for rank). We tested an undergraduate sample $(\mathrm{N}=70$, mean age $=21.5$ years $)$ and a clinical sample of predominantly depressed elderly ( $N=85$, mean age $=62.6$ years). Both rivalry and admiration-seeking increased with time on task and were particularly enhanced in individuals high in trait dominance or narcissism. Participants engaged in more rivalry when pitted against high-ranked opponents, a tendency accentuated by trait dominance and partially mitigated by depression. Our findings provide behavioral evidence that social dominance and narcissism manifest in increased rivalry and admiration-seeking during social contests. Depression does not suppress general competitiveness but selectively inhibits upward-focused rivalry.

Keywords: personality, status, social defeat, narcissism, depression, dominance 


\section{Highlights}

- Rivalry and admiration-seeking responses to social defeat were captured in an experimental task designed as a rigged video game tournament.

- Rivalry and admiration-seeking behaviors increased throughout the task and were further accentuated by trait dominance and narcissism.

- Social challenges were directed upwards, as evidenced by participants engaging in more rivalry against high-ranked opponents.

- Trait dominance further enhanced upward-focused rivalry.

- Depression did not decrease general competitiveness on the task but selectively inhibited efforts to dominate high-ranked opponents. 


\section{Introduction}

As primates whose survival and reproduction depend on our standing in a group, we integrate social comparisons, victories, and defeats into an implicit estimate of our social status or rank. Thus, we learn our place and decide how to best improve or maintain it (Barkow et al., 1975; Gilbert et al., 1995; Mahadevan et al., 2016). Our implicit rank is recalibrated following unexpected outcomes of social comparisons against others (Ligneul et al., 2016). Consistently, we tend to avoid confrontations with superiors without a reasonable probability of success (Gastorf et al., 1978) and prefer same-level comparisons, which give a better chance of increasing our status while remaining reasonably safe (Festinger, 1954). Individuals, as well as firms, political parties, and sports teams act more competitively when facing similarly-ranked counterparts than stronger ones (Dakin \& Arrowood, 1981; Hoffman et al., 1954; Kilduff et al., 2010; White \& Langer, 1999).

When threatened with social defeat, people tend to engage in self-enhancement, which aims to increase social rank, and in self-protection, which aims to avoid further losses by fleeing or fighting back (Alicke \& Sedikides, 2009). These competitive behaviors are subject to marked individual differences (Garcia et al., 2013), and can sometimes reach irrational and socially disadvantageous extremes (Geniole et al., 2017; Sivanathan \& Pettit, 2010). This paper explores behavioral responses to social defeat in narcissism and depressive states, linked by prior self-report and interview studies to opposite patterns of dominant and submissive behaviors (Johnson et al., 2012).

In narcissism, implicit rank is inflated (Gabriel et al., 1994) and also closely monitored (Krizan \& Bushman, 2011), which may confer certain fitness advantages. 
Fierce protection of one's dominant status (Brown \& Zeigler-Hill, 2004) may improve access to resources, and self-inflation improves mating chances (Dufner et al., 2013; Holtzman \& Donnellan, 2015). These strategies, however, can backfire when affiliationrather than dominance-driven responses are called for (Zeigler-Hill et al., 2018), for example during prolonged periods of adversity (Morf \& Rhodewalt, 2001). The prospect of losing status elicits intense emotions in highly narcissistic individuals (Rhodewalt \& Morf, 1998; Wright et al., 2017), and leads to counteroffensives to reassert dominance (Back, 2018). Back and colleagues termed narcissistic self-enhancement admirationseeking (seeking status through self-promotion), and narcissistic self-protection rivalry (antagonizing those perceived as threatening) (2013). Whereas healthy rivalry is attuned to the social rank of the opponent, highly narcissistic persons may engage in indisciminate rivalry (Horton \& Sedikides, 2009), often despite dire moral and financial consequences, and without explicit provocation (Böckler et al., 2017). At the same time, admiration-seeking takes a comparative form in more narcissistic individuals (Campbell et al., 2000), and is mostly directed towards high-status others (Horton \& Sedikides, 2009).

In contrast, depression is thought to shift priorities from achieving dominance to preventing conflict (Johnson et al., 2012; Price et al., 1994). Animals subordinated by aggressive conspecifics become socially avoidant and lack vigor in seeking rewards, a state mediated by plasticity in the mesostriatal pathway and reversed by antidepressants (Berton et al., 2006; Venzala et al., 2012). Consistently, subordinate mice display lower anxiety in situations of chronic social defeat than dominant mice (Larrieu et al., 2017). In humans, depressive states appear to deflate one's implicit rank (Battle, 1978), decrease 
social comparisons and increase submissive behavior when these characteristics are measured by self-reports (O'Connor et al., 2002). Conversely, assertively renegotiating one's role in key relationships is thought to be one mechanism of change in interpersonal therapy for depression (Lipsitz \& Markowitz, 2013). These findings suggest that behavioral and neural plasticity induced by social defeat constitutes one component of human depressive states. Thus depressive symptoms are expected to inhibit both rivalry and admiration-seeking in competitive environments.

In summary, while self-report studies describe broadly opposing reactions to social defeat in narcissism and depression, this concept's behavioral manifestations are yet to be tested experimentally. Toward this end, we investigated the effects of trait dominance, dimensionally-measured narcissism, and depression on self-protective and self-enhancing behaviors in situations of defeat in a competitive setting. Using a rigged video game tournament paired with a league table, we elicited rivalry (stealing points from opponents), and admiration-seeking (paying to increase one's rank), in an undergraduate sample and a clinical sample of predominantly depressed older adults. To uncover effects of implicit rank (i.e. self-perceived status) on these behaviors, our task manipulated the rank of opponents to examine whether rivalry and admiration-seeking were directed upwards or downwards in the social hierarchy. We expected $(\mathrm{H} 1 \mathrm{a})$ both rivalry and admiration-seeking to increase as a reaction to the cumulative experience of defeat throughout the task, with $(\mathrm{H} 1 \mathrm{~b})$ trait dominance and narcissism further enhancing both behaviors and $(\mathrm{H} 1 \mathrm{c})$ depression dampening them. With respect to the level of social comparisons, measured by rivalry and admiration-seeking as a function of the opponent's rank, we hypothesized that $(\mathrm{H} 2 \mathrm{a})$ it would be generally upward-focused, 
$(\mathrm{H} 2 \mathrm{~b})$ with an additional upward shift in high trait dominance and narcissism and $(\mathrm{H} 2 \mathrm{c}) \mathrm{a}$ downward shift in depression.

\section{Materials and Methods}

\section{$\underline{\text { Participants }}$}

Sample 1 was composed of 70 undergraduate students enrolled at the University of British Columbia, Vancouver, Canada (mean age 21.5 years), who participated (in individual sessions) for course credit. Sample 2 was composed of 85 adults aged 50 or older (mean age 62.6 years) participating in the Longitudinal Research Program in Latelife Suicide, in Pittsburgh, United States, a larger ongoing study (Szanto et al., 2015). Correlates of the present behavioral task with suicidal behavior in Sample 2 will be reported elsewhere. Participants from Sample 2 were originally recruited as 25 healthy subjects with no lifetime history of psychiatric disorder and 60 subjects with clinical levels of depression, scoring 14 or higher on the Hamilton Rating Scale for Depression (HRSD) upon study recruitment. The present study treated depression as a continuous variable in both samples. Significant effects were nevertheless tested in a categorical sensitivity analysis in Sample 2 (Supplemental Figure S3, Panel C). Sample characteristics can be found in Supplemental Table S1.

\section{Behavioral task}

We used a rigged video game tournament to elicit rivalry and admiration-seeking behaviors under a threat of social defeat (Figure 1). 


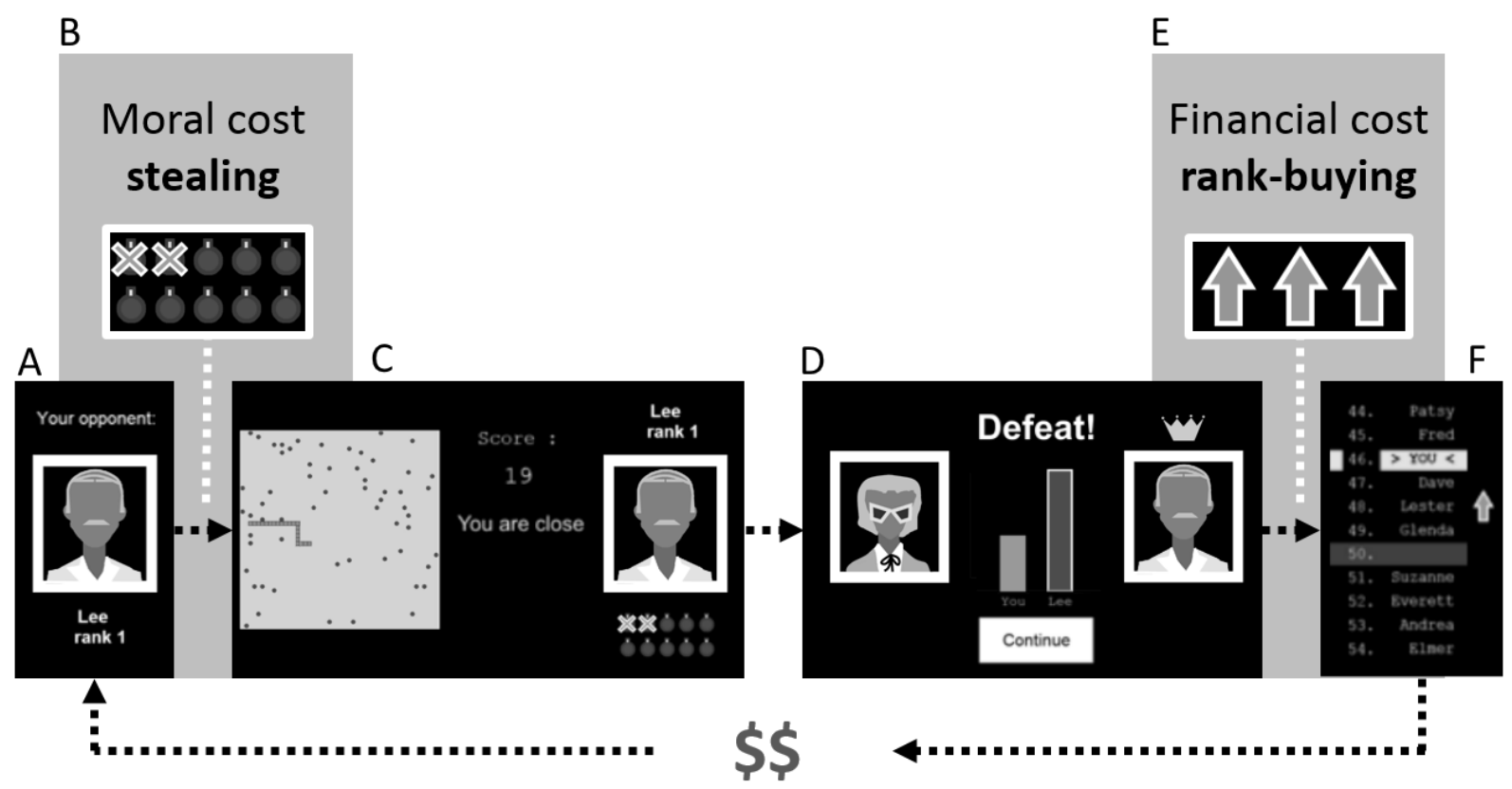

Figure 1: Task description. Each of the 24 trials has the following steps: A, new opponent is displayed with name and league rank (participants are told that these opponents are all previous players whose performance has been prerecorded); B, 1st outcome measure: willingness to steal points from the opponent's future score in order to increase one's chance of defeating him/her; C, playing the snake arcade game for 20 seconds, with the goal of gathering as many points (apples) as possible, while one's score (the number of apples caught) is displayed, as well as a message at 10 seconds informing the participant whether he/she is ahead, behind, or the outcome is close; D, learning the contest's outcome, which defines whether the participant will move 5 ranks up or down in the global ranking. These outcomes are rigged towards a $2: 1$ defeat to victory ratio occurring in a pseudorandom order; $\mathbf{E}, 2$ 2nd outcome measure: willingness to buy extra rank; $\mathbf{F}$, learning current rank in the competition. \$\$, each trial starts with a renewed virtual endowment that the participant can choose to spend on extra ranks. Participants are told that their real money payoff will be computed based on their savings from three random trials. Note. The computer version is in color.

The snake arcade game (adapted from the classic video game to Python 2.7) served as a basis to the competition and was embedded in a tournament interface programmed in Matlab, version 2016b. Each of the 24 trials was divided into a contest phase, when participants played a round of the snake arcade game against different opponents, and a ranking phase, where they gained or lost status in the tournament's league standings. Rivalry was measured by the willingness to steal points from the opponent before the contest (henceforth point stealing). Admiration-seeking was 
measured by the willingness to pay virtual money to increase one's rank in the league during the ranking phase (henceforth rank buying).

Whereas point stealing had a moral cost of being unfair and unsportsmanlike, participants were told that rank buying had a financial cost: they were instructed that their payment would be calculated based on the amount of virtual money saved on each trial, whereas their final standing in the game would not impact the payoff. The end-game payoffs were in fact the same for all participants.

To emulate a real-life social environment, participants were told they were playing against previous study participants whose performance had been recorded. To support this cover story, they chose an avatar to represent themselves in the game and entered a pseudonym; we instructed them not to use their real name, to preserve confidentiality. As a final step, participants were asked to choose whether they wanted to appear in the tournament's league table against future participants. Participants were in fact playing against virtual opponents, arranged in a pseudo-random order and paired with predefined outcomes, having an overall 2:1 defeat to victory ratio.

To mask the rigged outcomes, two additional manipulations were added during the arcade game: the commands from the original snake game were reduced to only the left/right arrow keys, turning the snake 90 degrees left or right on its own axis of reference; second, fewer apples (points) were available for collection on losing trials. The goal of these manipulations was to enhance the game's difficultly, and elicit feelings of frustration and helplessness due to poor performance (Reuderink et al., 2009). Finally, virtual monetary endowments and real money payoffs were adapted to each sample: in Sample 1, participants received 5 CAD (Canadian Dollars) as the trial-by-trial 
endowment and 7.50 CAD as the overall payoff, while in Sample 2, participants received 20 USD (U. S. Dollars) as the trial-by-trial endowment and 25 USD as the payoff.

The game recorded four subject-dependent variables. The two main outcome measures were participants' choices for point stealing (integers ranging from 1: no point stealing to 5: stealing 10 points from opponent) and rank buying (integers ranging from 1: no rank buying to 5: buying 5 extra ranks for half of the trial-by-trial endowment's amount). Additionally, the game recorded participants' own rank (recoded for analysis in an increasing order from $1=$ lowest rank to $200=$ highest rank) and scores (number of points on the snake arcade game) on each trial. These two additional subject-dependent variables were used as covariates during the analysis of the main outcome measures (see Statistical Analysis below). Scores were additionally employed in quality checks measuring game performance and task engagement (Supplemental Material, pp. 10-12).

\section{Other assessments}

At the beginning of the task, participants indicated their video game experience (integers ranging from 1: never played any games including smartphones and tablets to 5: playing every day). After the task, participants answered twelve additional questions about their motivations and impressions of the game that were examined in an exploratory analysis (Supplemental Figure S7).

Demographic characteristics (age, sex, ethnicity and household income) were collected at baseline. Due to divergence in data collection, household income was coded as an ordinal variable in Sample 1 and as logged amounts in Sample 2. Years of 
education were only assessed in Sample 2, as Sample 1 comprised undergraduates. Ethnicity and household income were missing in three participants of Sample 1.

Narcissism was assessed by the FFNI (Five-Factor Narcissism Inventory) (Sherman et al., 2015) and was treated as a continuous variable, given its dimensional structure corroborated by recent studies (Aslinger et al., 2018). The FFNI's distribution in our two samples can be found in Supplementary Figure S1. As a senstivity analysis testing the generalizability of our findings to the more pathological aspects of narcissism (Pincus et al., 2009, 2014), we additionally used the BPNI (Brief Pathological Narcissism Inventory), a 28-item version of the Pathological Narcissism Inventory (Schoenleber et al., 2015). We used total scores in our main analysis, but investigated whether specific dimensions of narcissism were driving the observed behavioral effects in an exploratory analysis including grandiose and vulnerable subscales of both the FFNI and the BPNI, and the agentic extraversion, antagonism, and narcissistic neuroticism subscales of the FFNI. The FFNI was missing in four participants of Sample 2. The BPNI was missing in one participant of Sample 1 and two participants of Sample 2.

Depression was assessed by the DASS-21 depression subscale in Sample 1 (Henry \& Crawford, 2005) and the Hamilton Rating Scale for Depression (HRSD) in Sample 2 (Hamilton, 1960).

Trait dominance was assessed in Sample 2 only by the IPIP-DS (International Personality Item Pool - Dominance Subscale) (Goldberg et al., 2006).

See Supplemental Table S2 for reliability coefficients of all psychometric measures and Supplemental Figure S2 for their correlations with task-related variables. 


\section{Procedure}

All procedures were in accordance with the Declaration of Helsinki, the Behavioural Research Ethics Board of the University of British Columbia for Sample 1 and the Institutional Review Board of the University of Pittsburgh for Sample 2. Participants played the task on a laptop computer in Sample 1 and Windows tablets in Sample 2. After they had given written, informed consent to participate, a research assistant walked them through the task instructions, a practice session, and a survey of their prior video game experience, all of which were built in the task. Participants then played the rigged video game tournament for 24 trials. The test administrator stayed in the room but did not watch participants' actions after the first two trials. After finishing the task, participants filled out the additional assessments (DASS-21, FFNI and BPNI scales for Sample 1; FFNI, BPNI and IPIP-DS for Sample 2). In Sample 2, the HRSD was administered by a clinician within a week of the task session in the form of a semistructured interview.

\section{$\underline{\text { Statistical Analysis }}$}

We examined how $(\mathrm{H} 1 \mathrm{a})$ defeat and $(\mathrm{H} 2 \mathrm{a})$ opponents' rank influenced rivalry and admiration-seeking throughout the task, and how $(\mathrm{H} 1 \mathrm{~b}, \mathrm{H} 2 \mathrm{~b})$ trait dominance and narcissism as well as $(\mathrm{H} 1 \mathrm{c}, \mathrm{H} 2 \mathrm{c})$ depression moderated these relationships. 


\section{Dependent variable and covariates}

All analyses were conducted in $\mathrm{R}$ version 3.4. Point stealing and rank buying were analyzed as continuous, trial-level variables that were person-mean centered around subject means, which resulted in a normal distribution. The person mean-centered scores were then entered as dependent variables in separate linear multi-level models (Ime4::Imer). As within-subject centering of choices yielded a variance of 0 in the subject intercept, associations between the subject's mean and subject-level variables were not tested. Instead, we examined increases in behavior in response to task manipulations, and interactions with subject-level variables modulating these relationships. All reported models include age, sex, education (in Sample 2 only), ethnicity, household income, game experience, and depression as co-variates. Unless specified otherwise, main effects' significance did not differ without the inclusion of these variables.

\section{Model selection}

On each step, model selection was performed using the likelihood-ratio test (function anova, package Stats). To diagnose multicollinearity, variance inflation factors adjusted for degrees of freedom were computed and were $<2$ for all reported effects of retained models.

First, the best-fitting model containing only design variables was selected in both samples. Three experimental condition effects central to our research questions were retained in all models: ( $\mathrm{H} 1 \mathrm{a})$ to investigate the effect of defeat, trial (time on task) measured overall exposure length to social defeat whereas most recent outcome (dummy-coded as 1 for victory and 0 for defeat) measured trial-by-trial positive/negative 
reinforcement on competitive behavior; $(\mathrm{H} 2 \mathrm{a})$ the level of social comparisons was measured as increases in behavior in response to the oppenent's rank (an integer between 1 = lowest rank and $200=$ highest rank). All models additionally included an indicator of performance on the snake arcade game (score on the most recent trial) and participants' current rank. Significant predictors in Sample 1 were maintained in models built for Sample 2, even when non-significant. In models predicting rank buying, previous rank-buying choices had to be entered as a covariate, since buying extra rank improved one's own status in the game (see Supplemental Figure S2 for correlations).

Second, we investigated the effects of trait dominance (measured by the IPIP-DS in sample 2 only), narcissism (measured by the FFNI in both samples) and depression (measured by the DASS-21 depression subscale in Sample 1 and the HRSD in Sample 2) by adding these psychometric constructs separately to the retained models with design variables, and allowing interactions between them. $(\mathrm{H} 1 \mathrm{~b}, \mathrm{H} 1 \mathrm{c})$ An interaction effect with trial or outcome would inform us about the psychometric construct's effect on the behavioral response to defeat, whereas $(\mathrm{H} 2 \mathrm{~b}, \mathrm{H} 2 \mathrm{c})$ an interaction with opponent's rank would suggest an effect on the level of social comparisons. In the case of narcissism, we further tested the effect with the BPNI and lower-level narcissistic dimensions.

Finally, we evaluated the retained models in a pooled analysis, in an effort to verify our results' consistency across age groups and levels of psychopathology. Including sample as an independent variable, we ran all selected models described above in a dataset encompassing both samples (with the exception of models including trait dominance, which was only available in Sample 2). The pooled analysis kept all 
subject-level covariates, which necessitated approximate conversions of household income, education and depression. Household income was recoded as a ranked variable in Sample 2 after conversion of the cut-off values used in Sample 1 from CAD to USD. The DASS-21 depression subscale in Sample 1 and the HRSD in Sample 2 were converted into percentile norms using a software tool developed by Crawford and colleagues in a general population sample (Crawford et al., 2011). Since percentile norms were not directly available for the HRSD, values of the Carroll Rating Scale for Depression were used instead, which is a self-report version of the HRSD that shares the same items and scoring (Carroll et al., 1981). Education was assumed to be 13 years in Sample 1.

Sensitivity analyses

We conducted four sensitivity analyses:

(a) To verify that our findings were truly reflecting behavioral changes arising in response to the task, we measured stereotypical response rates (responses with a variance of zero on a given outcome measure) between samples (Supplemental Table S3), compared stereotypical responders to the other participants on demographic and psychometric measures (Supplemental Table S4) and retested all main findings after excluding participants who engaged in stereotypical responding on both point stealing and rank buying (Supplemental Table S5).

(b) Given the well-established role of sex in competitive behaviors (Byrnes et al., 1999; Geniole et al., 2017) and the predominance of female participants in both of our samples (resp. $78.6 \%$ in Sample 1 and $60.0 \%$ in Sample 2; Supplemental Table S1), we 
tested all main findings' robustness to sex trial, sex outcome and sex ${ }^{*}$ opponent's rank covariates, added simultaneously to our selected models (Supplemental Table S6). We subsequently evaluated all main findings for moderation by sex, one interaction at a time (Supplemental Table S7).

(c) We tested our main findings in the pooled analysis for sample-level differences by letting sample moderate them.

(d) We investigated whether the effects found with the FFNI would generalize to the BPNI by substituting BPNI total scores to FFNI total scores in the models in question.

\section{Exploratory analyses}

We performed three additional exploratory analyses, in an effort to better situate our main findings within narcissistic dimensions and the task's general dynamics:

(a) Effects found with the FFNI total score were tested with both the FFNI's and the BPNI's subscales in the pooled analysis, to investigate which specific dimensions were driving them.

(b) We analyzed performance (scores on the snake arcade game) in linear mixedeffects models having subject-level intercepts as random effect (Supplemental Material, pp. 10-12, Supplemental Figure S5). This analysis enabled us to test differences between samples (Supplemental Figure S6, Panel A) and the effects of trait dominance, narcissism and depression on task engagement (Supplemental Figure S6, Panel B).

(c) As a final step in the pooled analysis, we looked at correlations of mean point stealing and rank buying behaviors and psychometric constructs with participants' self- 
reported motivations and impressions collected at the end of the task (Supplemental Figure S7). Our goal was to check whether the observed behaviors and their moderations by psychometric measures was consistent with how participants experienced the task.

\section{Results}

For the reader's convenience, below, we focus on replicated findings illustrated with statistics from the pooled analysis and only describe samplewise models in the main text in the case of inconsistencies (and for the trait dominance measure, collected only in Sample 2). Samplewise findings are further detailed in Supplemental Figures S3 and S4. Table 1 summarizes our main findings. 


\begin{tabular}{|c|c|c|c|}
\hline \multirow[t]{2}{*}{ Effects significant in the pooled analysis } & $\begin{array}{l}\text { Sample } 1 \\
(N=70)\end{array}$ & $\begin{array}{c}\text { Sample } 2 \\
(\mathrm{~N}=85)\end{array}$ & $\begin{array}{l}\text { Pooled } \\
(\mathrm{N}=155)\end{array}$ \\
\hline & \multicolumn{3}{|c|}{ Coefficient (standard error) } \\
\hline \multicolumn{4}{|c|}{ (i) Reaction to defeat } \\
\hline \multicolumn{4}{|c|}{ Point stealing } \\
\hline Point stealing increases over time & $.133(.026)^{\star \star \star}$ & $.115(.023)^{\star \star \star}$ & $.127(.017)^{\star \star \star}$ \\
\hline $\begin{array}{l}\text { Point stealing increases more over time in } \\
\text { participants with higher levels of trait dominance }\end{array}$ & $\begin{array}{l}\text { scale not } \\
\text { collected }\end{array}$ & $.062(.023)^{\star \star}$ & - \\
\hline $\begin{array}{l}\text { Point stealing increases more over time in } \\
\text { participants with higher levels of narcissism }\end{array}$ & $.027(.022)$ & $.046(.021)^{\star}$ & $.043(.015)^{\star \star}$ \\
\hline \multicolumn{4}{|c|}{ Rank buying } \\
\hline Rank buying increases over time & $.107(.025)^{\star \star \star}$ & $.045(.023)^{\star}$ & $.075(.017)^{\star \star \star}$ \\
\hline $\begin{array}{l}\text { Rank buying increases more over time in participants } \\
\text { with higher levels of trait dominance }\end{array}$ & $\begin{array}{l}\text { scale not } \\
\text { collected }\end{array}$ & $.051(.021)^{\star}$ & - \\
\hline $\begin{array}{l}\text { Rank buying increases more over time in participants } \\
\text { with higher levels of narcissism }\end{array}$ & $.057(.024)^{\star}$ & $.043(.021)^{\star}$ & $.051(.015)^{\star \star \star}$ \\
\hline \multicolumn{4}{|c|}{ (ii) Level of social comparisons } \\
\hline \multicolumn{4}{|c|}{ Point stealing } \\
\hline $\begin{array}{l}\text { Point stealing increases against high-ranked } \\
\text { opponents }\end{array}$ & $.068(.024)^{\star \star}$ & $.095(.022)^{\star \star \star}$ & $.085(.016)^{\star \star \star}$ \\
\hline $\begin{array}{l}\text { Point stealing increases more against high-ranked } \\
\text { opponents after having performed well on the arcade } \\
\text { game }\end{array}$ & $.046(.021)^{\star}$ & $.051(.019)^{\star \star}$ & $.032(.014)^{\star}$ \\
\hline $\begin{array}{l}\text { Point stealing increases against high-ranked } \\
\text { opponents in participants with higher levels of trait } \\
\underline{\text { dominance }}\end{array}$ & $\begin{array}{l}\text { scale not } \\
\text { collected }\end{array}$ & $.071(.021)^{\star \star \star}$ & - \\
\hline $\begin{array}{l}\text { Point stealing does not increase against high-ranked } \\
\text { opponents in highly depressed participants }\end{array}$ & $-.031(.024)$ & $-.064(.019)^{\star \star \star}$ & $-.057(.014)^{\star \star \star}$ \\
\hline \multicolumn{4}{|c|}{ Rank buying } \\
\hline $\begin{array}{l}\text { Rank buying increases more over time against high- } \\
\text { ranked opponents }\end{array}$ & $.059(.021)^{\star \star}$ & $.008(.020)$ & $.030(.014)^{\star}$ \\
\hline
\end{tabular}

Table 1: Summary of main findings in the two samples and in the pooled analysis encompassing both. Significant effects are in bold. Legend: ${ }^{*}, p<.05 ;{ }^{* *}, p<.01 ;{ }^{* *}, p<.001$. 


\section{(H1) Reaction to defeat}

(H1a) We found no effect of the immediately preceding outcome. However, over the task both point stealing and rank buying increased in reaction to defeat, as evidenced by a main effect of $\operatorname{trial}\left(X^{2}{ }_{1}=55.33, p<.001\right.$ for point stealing; $X^{2}{ }_{1}=20.11, p$ $<.001$ for rank buying; Figure 2).

(H1b) Trait dominance predicted greater increases in both point stealing and rank buying over time, as indicated by a trait dominance*trial interaction in Sample 2, where the IPIP-DS was administered $\left(X^{2}{ }_{1}=7.45, p=.006\right.$ for point stealing; $X^{2}{ }_{1}=5.90, p=.015$ for rank buying; Figure 3A). Similarly, narcissism increased point stealing and rank buying over time $\left(X^{2}{ }_{1}=7.91, p=.005\right.$ for point stealing; $X^{2}{ }_{1}=11.28, p<.001$ for rank buying; Figure 3, Panel B). The narcissism*trial effect was not significant in the model predicting point stealing in Sample 1, but shared a similar pattern in all other cases (Supplemental Figure S3, Panel A).

(H1c) Depression did not influence point stealing and rank buying over time. 


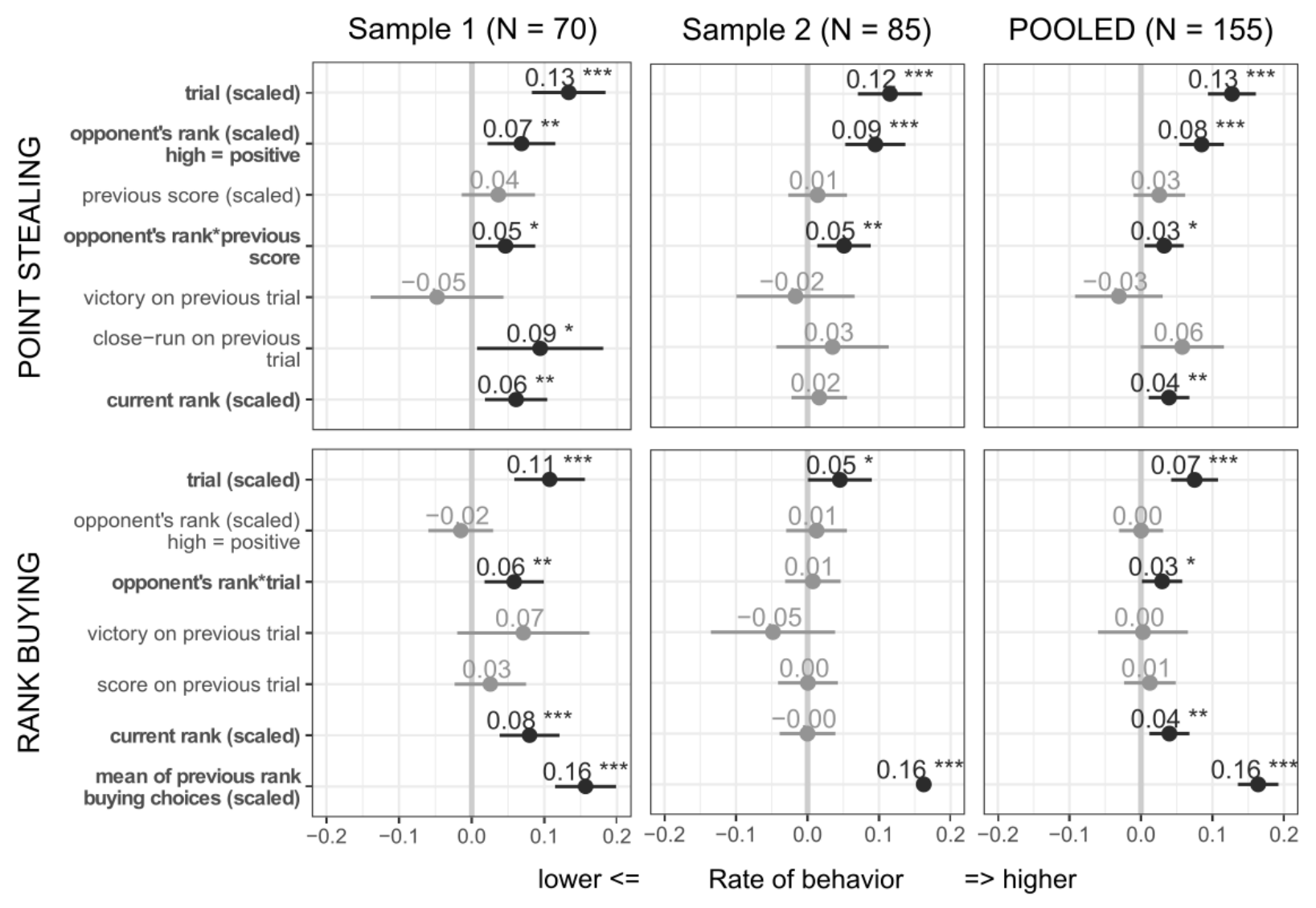

Figure 2: Models with design variables predicting point stealing and rank buying in the two samples and the pooled analysis. Estimates of demographic covariates present in the models are not displayed (age, sex, ethnicity, household income, education, game experience, depression); effects significant in the pooled analysis are in bold, significant coefficients within each table appear in darker gray. The significant positive effect of trial (i.e. time on task) on both point stealing and rank buying behaviors can be interpreted as a reaction to the increasing exposure to defeat (given the rigged outcomes). Opponent's rank and player's previous score ${ }^{*}$ opponent's rank were consistent predictors of point stealing across samples, indicating a preference for upward directed rivalry, especially after having performed well on the snake arcade game. The mean of previous rank-buying choices was included as a covariate in the model predicting rank buying since buying extra rank inflated participant's own rank (see Methods Statistical Analysis - Model Selection). Points and numbers indicate estimates of fixed effects; horizontal bars represent standard errors. Legend: ${ }^{*}, p<.05 ;{ }^{* *}, p<.01 ;{ }^{* * *}, p<.001$. 
Panel A: Trait dominance*trial effects predicting point stealing and rank buying (Sample 2)
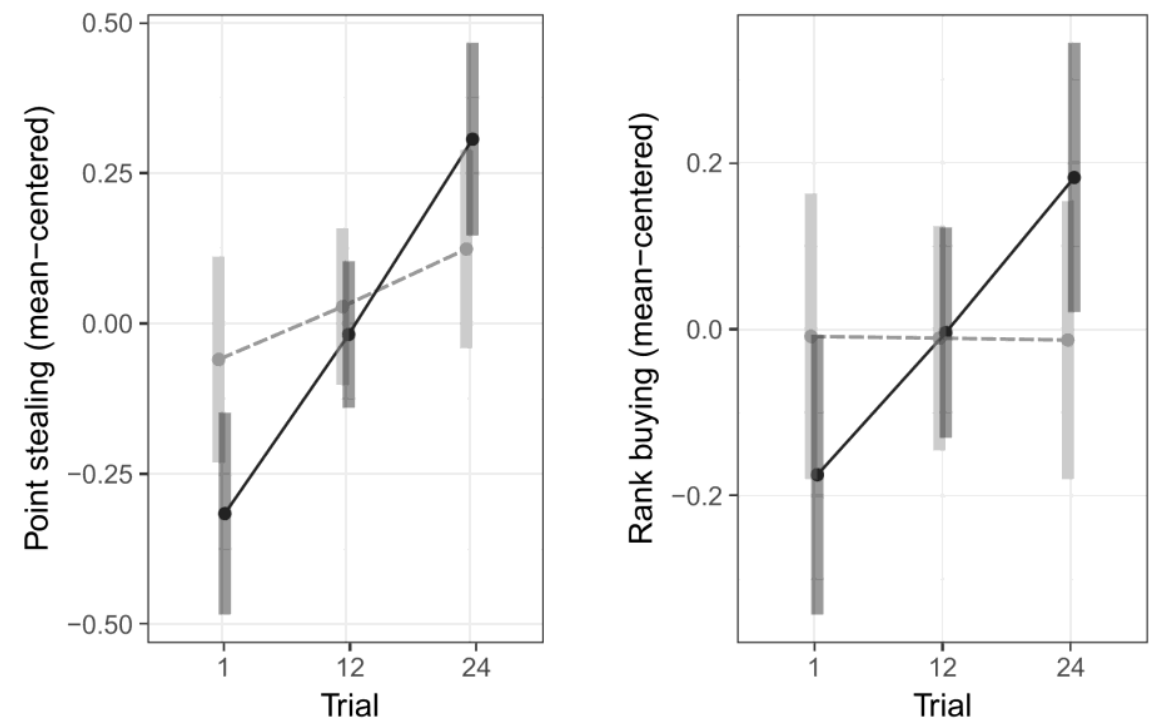

IPIP-DS:

18 (mean - 1 SD)

$\rightarrow-35($ mean $+1 \mathrm{SD})$

Panel B: Narcissismtrial effects predicting point stealing and rank buying (Pooled analysis)
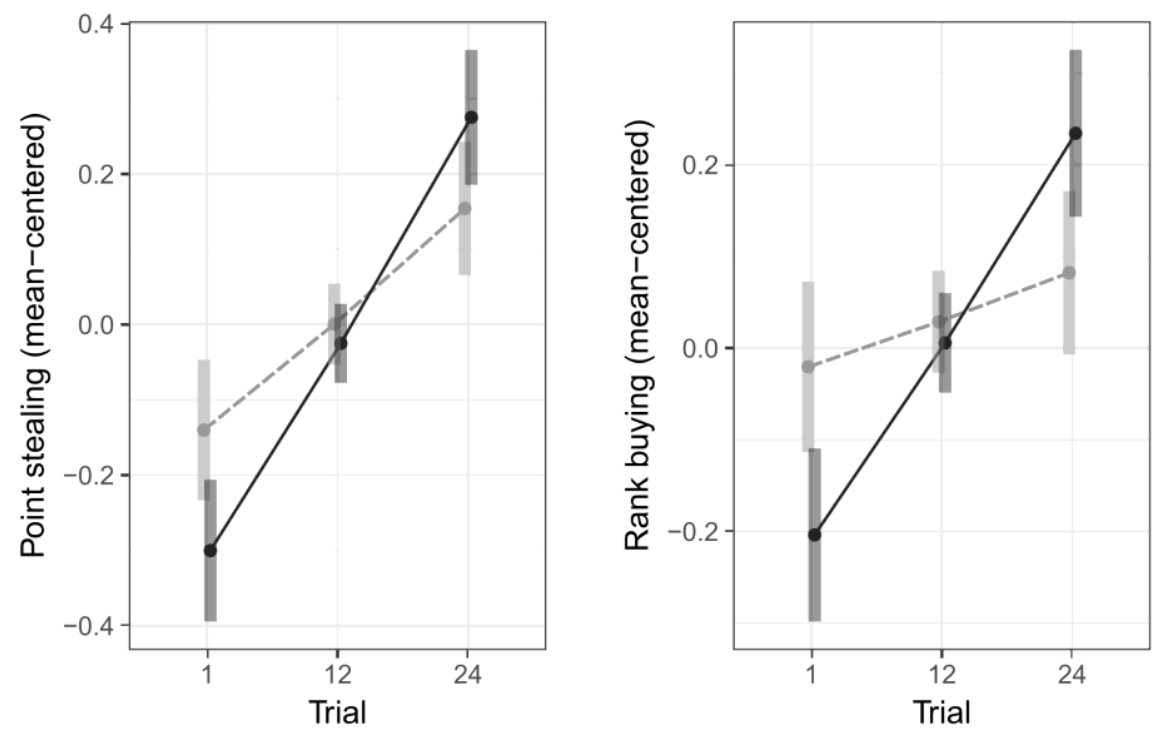

FFNI:

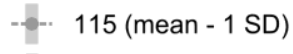

$\rightarrow 171($ mean $+1 \mathrm{SD})$

Figure 3, Panel A: Significant trait dominance*trial interactions predicting point stealing and rank buying, indicating that individuals high on trait dominance tended to increase both behaviors in response to the cumulative experience of defeat. A trait dominance measure was only collected in Sample 2. Panel B: Significant narcissismtrial interactions predicting point stealing and rank buying. Similarly to trait dominance, narcissism increased point stealing and rank buying throughout time (number of trials). All above effects were robust to subject-level covariates (age, sex, education, ethnicity, household income, game experience and depression). Points are estimates from the corresponding regression model at the indicated values; vertical bars represent 95\% confidence intervals. Legend: FFNI, Five-Factor Narcissism Inventory. 


\section{(H2) Level of social comparisons}

For clarity, effects on the level of social comparisons are detailed separately for point stealing and rank buying.

\section{Point stealing}

(H2a) With respect to point stealing, our models with design variables indicated that people stole more points when pitted against high-ranked opponents $\left(X^{2}{ }_{1}=28.33, p\right.$ $<.001)$ and even more so when facing a high-ranked opponent after achieving a high score on the previous round (opponent's rank ${ }^{*}$ previous score: $X^{2}{ }_{1}=5.42, p=.020$ ).

(H2b) A positive trait dominance*opponent's rank interaction predicting point stealing $\left(x^{2}{ }_{1}=10.90, p=.001\right)$ indicated that participants with higher levels of trait dominance preferentially engaged in point stealing against high-ranked opponents (Figure 4). No moderation effect was present with narcissism. 


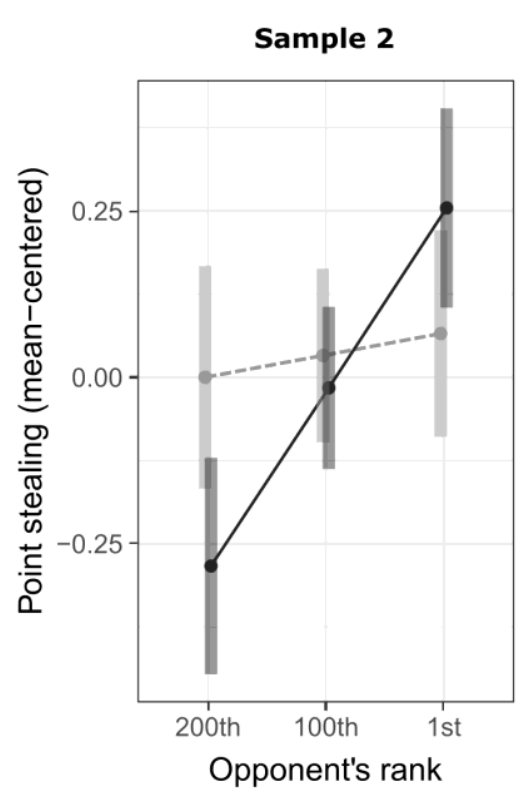

IPIP-DS:

$18($ mean - 1 SD) $\rightarrow-35($ mean + 1SD $)$

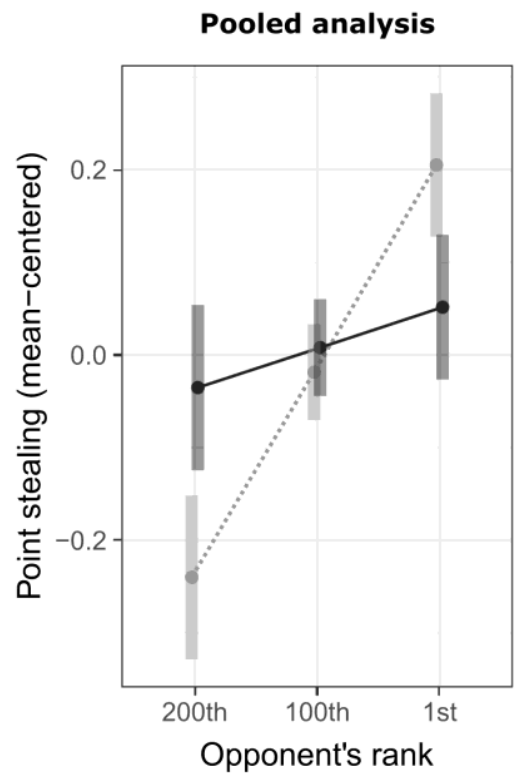

Depression (percentile norms):

*.. 31 (mean - 1SD) $\rightarrow 91($ mean + 1SD)

Figure 4, left panel: Significant trait dominance*opponent's rank interaction predicting point stealing, indicating that individuals high on trait dominance preferentially stole points from high-ranked opponents. A trait dominance measure was only collected in Sample 2. Right panel: Significant depression*opponent's rank interaction predicting point stealing. By contrast to participants high on trait dominance, more depressed individuals failed to adjust point stealing to their opponents' rank. Points are estimates from the corresponding regression model at the indicated values; vertical bars represent 95\% confidence intervals. Legend: IPIP-DS, International Personality Item Pool Dominance Subscale.

(H2c) By contrast, a depression*opponent's rank interaction predicting point stealing $\left(X^{2}{ }_{1}=16.79, p<.001\right.$; Figure 4$)$ evidenced a consistent loss of sensitivity to opponents' rank among more depressed participants. After the inclusion of subject-level covariates, this effect fell short of significance when tested separately in Sample 1 (Supplemental Figure S3, Panel B), where depression scores were tightly distributed around the population average (Supplemental Table S1). In Sample 2, the effect was robust to covariates and remained present when depression was analyzed categorically $\left(X^{2}{ }_{1}=9.33, p=.002 ;\right.$ Supplemental Figure S3, Panels B and C) 
Rank buying

(H2a) Rank buying was not higher against high-ranked opponents overall, but did increase more against them over time, as evidenced by an opponent's rank*trial interaction $\left(x^{2}{ }_{1}=4.22, p=.040\right)$. This effect was not significant in Sample 2 .

$(\mathrm{H} 2 \mathrm{~b}, \mathrm{H} 2 \mathrm{c})$ We found no interactions of opponent's rank with trait dominance, narcissism or depression predicting rank buying in the pooled analysis. Initial narcissism*opponent's rank ${ }^{*}$ trial and narcissism*opponent's rank effects found in Sample 1 (resp. $X^{2}{ }_{1}=4.40, p=.036$ and $X^{2}{ }_{1}=4.75, p=.029$; Supplemental Figure S4) were no longer significant in Sample 2 and in the pooled models, and were therefore not retained among our main findings.

\section{Sensitivity analyses}

(a) Stereotypical response rates were consistent across samples. Stereotypical responders represented respectively 12 and $13 \%$ of participants in Sample 1 and 2 (Supplemental Table S3). They did not differ from other subjects, with the exception of none being African-American in Sample 2 vs. $18.7 \%$ in the rest of the sample (Supplemental Table S4). Excluding stereotypical responders from the analysis did not change any of our main findings (Supplemental Table S5).

(b) Including sex*trial, sex*outcome and sex*opponent's rank did not influence our main findings either in the pooled analysis, or in the individual samples, with the exception of the main effect of trial on rank buying that lost significance in Sample 2 but maintained comparable effect magnitude to the principal model (Supplemental Table S6). Interaction effects with sex were not significant in models predicting point stealing 
(Supplemental Table S7). With respect to rank buying, negative sex*trial and sex ${ }^{*}$ trial ${ }^{*}$ opponent's rank effects emerged in the pooled analysis (resp. $X^{2}{ }_{1}=6.72, p=$ .010 and $\left.x^{2}{ }_{1}=7.96, p=.0047\right)$, the former being only significant in Sample $1\left(x^{2} 1=7.22\right.$, $\mathrm{p}=.007)$ and the latter in Sample $2\left(\mathrm{x}^{2}{ }_{1}=4.71, \mathrm{p}=.030\right)$. Sex did not moderate effects of trait dominance, narcissism or depression.

(c) Our main findings did not generally differ across samples in the pooled analysis, with the following exceptions: a sample*opponent's rank interaction predicting point stealing $\left(\mathrm{x}^{2}{ }_{1}=4.70, \mathrm{p}=.030\right)$ and a sample ${ }^{*}$ trial interaction predicting rank buying $\left(X^{2} 1=5.10, p=.024\right)$ indicated similar effect directions in both samples, but a greater effect magnitude, respectively, in Sample 2 for opponent's rank predicting point stealing and in Sample 1 for trial predicting rank buying.

(d) Similar narcissism*trial effects were found with the BPNI as with the FFNI in the pooled analysis $\left(X^{2}{ }_{1}=7.65, p=.006\right.$ for point stealing; $X^{2}{ }_{1}=4.33, p=.038$ for rank buying; Table 2). In the individual Samples, this effect did only reach significance for point stealing in Sample $1\left(x^{2}{ }_{1}=3.97, p=.046\right)$. 


\begin{tabular}{|c|c|c|}
\hline \multirow{2}{*}{$\begin{array}{l}\text { Main effects of interest for narcissism, as } \\
\text { measured by the FFNI }\end{array}$} & FFNI & BPNI \\
\hline & \multicolumn{2}{|c|}{ Coefficient (standard error) } \\
\hline \multicolumn{3}{|c|}{ Reaction to defeat (narcissism*trial interaction) } \\
\hline \multicolumn{3}{|c|}{ Point stealing } \\
\hline TOTAL SCORE & $.043(.015)^{\star \star}$ & $.043(.016)^{\star \star}$ \\
\hline Grandiosity & $.039(.015)^{\star \star}$ & $.039(.016)^{\star}$ \\
\hline Vulnerability & $.024(.015)$ & $.040(.016)^{\star}$ \\
\hline Agentic extraversion & $.041(.015)^{\star \star}$ & \multirow{3}{*}{-} \\
\hline Antagonism & $.024(.015)$ & \\
\hline Narcissistic neuroticism & $.018(.015)$ & \\
\hline \multicolumn{3}{|c|}{ Rank buying } \\
\hline TOTAL SCORE & $.063(.017)^{\star \star \star}$ & $.032(.016)^{\star}$ \\
\hline Grandiosity & $.042(.015)^{\star \star}$ & $.034(.015)^{\star}$ \\
\hline Vulnerability & $.038(.015)^{\star}$ & $.027(.016)$ \\
\hline Agentic extraversion & $.031(.015)^{\star}$ & \multirow{3}{*}{-} \\
\hline Antagonism & $.035(.015)^{\star}$ & \\
\hline Narcissistic neuroticism & $.015(.015)$ & \\
\hline
\end{tabular}

Table 2: Effects of BPNI narcissism and of lower-level dimensions in the pooled analysis. Legend: FFNI, Five-Factor Narcissism Inventory; BPNI, Brief Pathological Narcissism Inventory; *, $\mathrm{p}<.05 ;{ }^{* *}, \mathrm{p}<.01 ;{ }^{* * *}, \mathrm{p}<.001$.

\section{Exploratory analyses}

(a) With respect to lower-level narcissism dimensions (Table 2), no clear specificity emerged, with nevertheless higher consistency of effects with grandiosity than with vulnerability. In terms of the FFNI's three-factor subdivision, agentic extraversion was associated with both point stealing and rank buying (resp. $X^{2}{ }_{1}=7.28, p=.007$ and $\left.X^{2}{ }_{1}=4.28, p=.039\right)$, antagonism with rank buying $\left(X^{2}{ }_{1}=5.54, p=.019\right)$ and narcissistic neuroticism with none of the behaviors.

(b) Task performance, as measured by scores on the snake arcade game increased with time $\left(X^{2}{ }_{1}=104.95, p<.001\right.$ ), albeit less steeply in Sample 2 (trial ${ }^{*}$ sample interaction in the pooled analysis: $\left.X^{2}{ }_{1}=12.44, p<.001\right)$. Trait dominance and narcissism 
further accentuated performance over time $\left(x^{2}{ }_{1}=6.67, p=.010\right.$ for trait dominance in Sample 2, where the scale was collected; $x^{2}{ }_{1}=7.65, p=.006$ for narcissism in the pooled analysis). In the case of narcissism, this effect was driven by grandiosity as measured by both the FFNI and the BPNI (resp. $X^{2}{ }_{1}=10.34, p=.001$ and $X^{2}{ }_{1}=7.50, p=$ $.006)$ and in the FFNl's three factor subdivision, by agentic extraversion $\left(X^{2} 1=8.98, p=\right.$ $.003)$ and to a lesser extent by antagonism $\left(x^{2} 1=4.12, p=.042\right)$. Antagonism however also predicted lower scores overall $\left(X^{2}{ }_{1}=4.37, p=.037\right)$, as did FFNI and BPNI vulnerability subscales (resp. $X^{2}{ }_{1}=6.85, p=.009$ and $X^{2}{ }_{1}=10.02, p=.002$ ). Depression predicted lower scores overall $\left(X^{2}{ }_{1}=4.53, p=.033\right)$, without influencing improvement over time. For further details, see Supplemental Material pp. 10-12, Supplemental Figures S5 and S6 and Supplemental Table S8.

(c) Correlations of mean behaviors and psychometric measures with participants' self-reported feedback can be found in Supplemental Figure S7. Mean point stealing and rank buying respectively correlated at .24 and .26 with striving for status (question M5) and at .31 and .20 with striving for victory (question M8). Seeking to outperform others (question M3) and avoiding being worse than everyone else (question M4) additionally correlated with mean point stealing at respectively .25 and .17. Judging one's own performance favorably correlated with rank buying at .20 (question A4). It also had a positive correlation with FFNI grandiosity and agentic extraversion (resp. .19 and .23) and a negative one with FFNI vulnerability and narcissistic neuroticism (resp -.17 and .16). Depression and both FFNI and BPNI vulnerability subscales negatively correlated with enjoyment of the task (resp. -.26 and -.25 and -.22; question A3) and with believed fairness of opponents (resp. -.17 and -.19 amd -.23; question A2), whereas FFNI 
grandiosity and agentic extraversion positively correlated with striving for status (resp .20 and .27; question M5); striving for victory (resp .19 and .20; question M8), seeking to outperform others (resp. .20 and .24; question M3) and seeking revenge (resp .22 and .17 ; question M6). FFNI antagonism correlated with seeking revenge at .26 (question M6) and striving for victory at .16 (question M8).

\section{Discussion}

We used a rigged video game tournament experiment to elicit rivalry and admiration-seeking behaviors and investigate the level of social comparisons under the threat of defeat. We observed an increase of both behaviors with time on task, which was enhanced by trait dominance and narcissism. In contrast, depression did not inhibit these behaviors, against our prediction. With respect to the level of social comparisons, we found that upward-focused rivalry was accentuated by trait dominance and inhibited by depression. However, we observed no consistent effect of narcissism on the level of social comparisons. Taken together, our findings are consistent with the maintainance of social status constituting a general human motivation (Anderson et al., 2015), and further suggest that this goal is moderated by narcissism and depression on two distinct levels, both of which are linked to dominance: while narcissism primarily increases the intensity of rivalry and admiration-seeking, depression influences rivalry's objective, by inhibiting upward-focused ambitions.

Experimentally corroborating the rivalry/admiration theory (Back et al., 2013), more narcissistic persons were more intensely motivated to protect and promote their implicit rank in the face of social defeat (Figure 3, Panel B). Similarly to Back and 
colleagues (Back et al., 2013), we observed that these behaviors were the most consistent in grandiose and agentic extraversion dimensions, but that they also occured in more pathological forms of narcissism, as evidenced by similar albeit less consistent findings with the BPNI overall and with the vulnerability subscales of both narcissism measures (Table 2). Further, these behaviors scaled in similar ways with trait dominance as with narcissism (Figure 3, Panel A), which was consistent with overlapping dominance-driven motivations between the two constructs, as outlined in the Dominance Behavioral System (Johnson et al., 2012). Both narcissism and trait dominance also correlated with faster improvement in performance on the snake arcade game (Supplemental Figure S6, Panel B), corroborating the increase in adaptive competitiveness found in narcissism, in particular in grandiose narcissism (Luchner et al., 2011).

The fact that participants high in narcissism started the task with lower rates of rivalry and admiration-seeking than their less narcissistic counterparts (Figure 3, Panel B) is consistent with these behaviors' compensatory role. Narcissism has been linked to overestimating one's future performance (Farwell \& Wohlwend-Lloyd, 1998), suggesting that more narcissistic participants only resorted to alternative pathways once their own performance appeared insufficient to achieve dominance. This finding supports the recently developed SPIN (Status Pursuit In Narcissism) model, which suggests that rivalry arises when primary admiration-based pathways to status are hindered, such as the possibility to win the tournament by playing well on our rigged task (Grapsas et al., 2020). Yet, in our paradigm, more narcissistic participants pursued admiration-seeking (paying for rank) simultaneously with rivalry. This suggests that obtaining status by 
achieving dominance over others remained important for participants independently of achieving status by self-promotion, similarly to what is described in the dominanceprestige model of status pursuit (Cheng, 2013).

Interestingly, only admiration-seeking was enhanced by narcissistic antagonism (Table 2), which in turn correlated with revenge motivations (Supplemental Figure S7). Rivalry in our paradigm matched Back's definition (Back, 2018), namely a willingness to surpass and devalue others in a socially insensitive way and consistently correlated with the self-reported motivation of outperforming others (Supplemental Figure S7). However, given that point stealing occured before playing against a given opponent, our measure of rivalry did not include a component of revenge. On the other hand, our measure of admiration-seeking (rank buying) took place right after learning the trial's outcome and thus likely acquired a rivalry component. This is also suggested by the increase over time of rank buying against high-ranked opponents (Table 1). Consistently, prior research found that self-enhancing/admiration-seeking can also be dominance- not only prestige-based (Zeigler-Hill et al., 2019), and could take an upward-focused, comparative form (Campbell et al., 2000; Horton \& Sedikides, 2009). More generally, our findings highlight the complexity of social competion dynamics that tend to entangle the motivations underlying rivalry and admiration-seeking behaviors in real life.

Consistently with our second hypothesis with respect to most intense social comparisons, rivalry was preferentially upward-focused, and this was enhanced by trait dominance (Figure 4, left panel). Although our paradigm did not test participants' preferred level of social challenges, which may have reflected their implicit rank more directly (Festinger, 1954), a strong performance on the previous trial further accentuated 
rivalry against high-ranked opponents, supporting an upward shift in implicit rank and an increase in assertiveness after positive prediction errors about one's capability (Ligneul et al., 2016; Mahadevan et al., 2016).

In contrast, depression inhibited upward-directed rivalry (Figure 4, right panel). This was not explained by a lack of engagement in the task, as indicated by intact performance improvement in more depressed individuals (Supplemental Material, p. 11). Nor was it due to decreased competitiveness, since depression did not inhibit point stealing. Depressed individuals exhibited rivalry in a manner insensitive to others' rank and were not selectively motivated to dominate high-status others. Depression has been found to correlate positively with performance-avoidance goals, i.e. trying not to underperform compared to others, and negatively with performance-approach goals, i.e. aiming to outperform others (Sideridis, 2005). Further, depressive individuals' insecurity about their own social rank has been found to prompt competitiveness primarily out of fear of inferiority and of subsequent rejection (Gilbert et al., 2009). Thus, the observed behavioral patterns align with the social competition hypothesis of depression, stating that by down-regulating dominance motivations, depression grants survival to presumably weaker individuals in a hostile environment (Price et al., 1994). Yet, our findings leave the question open whether depression's dominance-inhibiting effect stems from lower implicit rank, as suggested by some (Gilbert et al., 2009; Mahadevan et al., 2016; Sullivan, 1953), and if this effect follows a vicious cycle, sustaining lower implicit rank by impeding higher-level social achievements, as outlined in interpersonal theory (Safran \& Greenberg, 1988). 
The strengths of our study include the nuanced and novel experimental assessment of competitive behavior dynamics and sensitivity to social hierarchy. Our findings' consistency across two very different samples in terms of age and psychopathology and their robustness to sex differences and other demographic covariates add to their generalizability. As limitations, we note the moderate sizes of each individual sample and the absence of a trait dominance measure in Sample 1. In addition, the weaker manipulation effects in Sample 2 could be due to older adults' lower cognitive functioning and/or relative inexperience with the video game interface. Our participants were not specifically sampled for high/pathological levels of narcissism, since most of the conceptual frameworks relevant to our paradigm have focused on normally distributed subclinical narcissistic traits (Back et al., 2013; Grapsas et al., 2020; Mahadevan et al., 2016). Future research should nonetheless explore how our behavioral findings map on narcissism's more pathological forms, namely narcissistic personality disorder. Finally, although the admiration and rivalry framework developed by Back and colleagues heavily informed our thinking when building our paradigm (Back et al., 2013), the Narcissistic Admiration and Rivalry Questionnaire (NARQ) was not used in the current study. The NARQ should be included in future works to calibrate our behavioral measures of rivalry and admiration to self-report items.

Our approach not only captured behaviors that map on narcissistic and depressive semiology, such as narcissistic dominance-striving or depressive dominanceinhibition, but also dissected how these tendencies are expressed in social defeat. The decisional biases highlighted by our findings are likely reflected in everyday behavior in both general and clinical populations. The fact that social defeat and status can be 
successfully manipulated experimentally trial-by-trial in real time opens the way for the study of their physiological and neural correlates, going beyond the classic bargaining games predominantly employed to date.

Acknowledgement: The authors acknowledge Laura Kenneally for help with the manuscript as well as Maria Alessi, Amanda Collier, Laura Kenneally and Michelle Perry for their work on data collection.

Financial support: This work was supported by the the National Institute of Mental Health, Maryland, USA (A.D., grant numbers R01MH048463, R01MH100095), (K.Sz., grant number R01MH085651-11).

Declarations of interest: none.

Ethical standards: The authors assert that all procedures contributing to this work comply with the ethical standards of the relevant national and institutional committees on human experimentation and with the Helsinki Declaration of 1975, as revised in 2008.

Author Contributions: A.D. and K.Sz. conceived and directed the project. A.S., K.Sz., L.C and A.D. designed the task. A.W. contributed to the conceptual framework. A.S. coded and piloted the task. J.A. adapted the task's interface to the undergraduate Sample 1 and administered the task to that sample. A.S. and A.D. analyzed the data. All authors participated in data interpretation. A.S. drafted the manuscript. K.Sz, L.C., A.W. and A.D. helped with the development of the manuscript. 


\section{References}

Alicke, M. D., \& Sedikides, C. (2009). Self-enhancement and self-protection: What they are and what they do. European Review of Social Psychology, 20(1), 1-48.

Anderson, C., Hildreth, J. A. D., \& Howland, L. (2015). Is the desire for status a fundamental human motive? A review of the empirical literature. Psychological Bulletin, 141(3), 574601. https://doi.org/10.1037/a0038781

Aslinger, E. N., Manuck, S. B., Pilkonis, P. A., Simms, L. J., \& Wright, A. G. (2018). Narcissist or narcissistic? Evaluation of the latent structure of narcissistic personality disorder. Journal of Abnormal Psychology, 127(5), 496.

Back, M. D. (2018). The Narcissistic Admiration and Rivalry Concept. In A. D. Hermann, A. B. Brunell, \& J. D. Foster (Eds.), Handbook of Trait Narcissism (pp. 57-67). Springer International Publishing. https://doi.org/10.1007/978-3-319-92171-6_6

Back, M. D., Küfner, A. C. P., Dufner, M., Gerlach, T. M., Rauthmann, J. F., \& Denissen, J. J. A. (2013). Narcissistic admiration and rivalry: Disentangling the bright and dark sides of narcissism. Journal of Personality and Social Psychology, 105(6), 1013-1037. https://doi.org/10.1037/a0034431

Barkow, J. H., Akiwowo, A. A., Barua, T. K., Chance, M., Chapple, E. D., Chattopadhyay, G. P., Freedman, D. G., Geddes, W., Goswami, B., \& Isichei, P. (1975). Prestige and culture: A biosocial interpretation [and comments and replies]. Current Anthropology, 16(4), 553572.

Battle, J. (1978). Relationship between self-esteem and depression. Psychological Reports, 42(3), 745-746.

Berton, O., McClung, C. A., DiLeone, R. J., Krishnan, V., Renthal, W., Russo, S. J., Graham, D., Tsankova, N. M., Bolanos, C. A., Rios, M., Monteggia, L. M., Self, D. W., \& Nestler, E. J. (2006). Essential Role of BDNF in the Mesolimbic Dopamine Pathway in Social Defeat Stress. Science, 311(5762), 864-868. https://doi.org/10.1126/science.1120972

Böckler, A., Sharifi, M., Kanske, P., Dziobek, I., \& Singer, T. (2017). Social decision making in narcissism: Reduced generosity and increased retaliation are driven by alterations in perspective-taking and anger. 104, 1-7.

Brown, R. P., \& Zeigler-Hill, V. (2004). Narcissism and the non-equivalence of self-esteem measures: A matter of dominance? Journal of Research in Personality, 38(6), 585-592. https://doi.org/10.1016/j.jrp.2003.11.002

Byrnes, J. P., Miller, D. C., \& Schafer, W. D. (1999). Gender Differences in Risk Taking: A MetaAnalysis. 125(3), 367-383.

Campbell, W. K., Reeder, G. D., Sedikides, C., \& Elliot, A. J. (2000). Narcissism and Comparative Self-Enhancement Strategies. Journal of Research in Personality, 34(3), 329-347. https://doi.org/10.1006/jrpe.2000.2282

Carroll, B. J., Feinberg, M., Smouse, P. E., Rawson, S. G., \& Greden, J. F. (1981). The Carroll rating scale for depression I. Development, reliability and validation. The British Journal of Psychiatry, 138(3), 194-200.

Cheng, J. T. (2013). Two ways to the top: Evidence that dominance and prestige are distinct yet viable avenues to social rank. 104(1). https://doi.org/10.14288/1.0074049 
Crawford, J., Cayley, C., Lovibond, P. F., Wilson, P. H., \& Hartley, C. (2011). Percentile Norms and Accompanying Interval Estimates from an Australian General Adult Population Sample for Self-Report Mood Scales (BAI, BDI, CRSD, CES-D, DASS, DASS-21, STAI$\mathrm{X}, \mathrm{STAI}-\mathrm{Y}, \mathrm{SRDS}$, and SRAS): Percentile norms for mood scales. Australian Psychologist, 46(1), 3-14. https://doi.org/10.1111/j.1742-9544.2010.00003.x

Dakin, S., \& Arrowood, A. J. (1981). The social comparison of ability. Human Relations, 34(2), 89-109.

Dufner, M., Rauthmann, J. F., Czarna, A. Z., \& Denissen, J. J. A. (2013). Are Narcissists Sexy? Zeroing in on the Effect of Narcissism on Short-Term Mate Appeal. Personality and Social Psychology Bulletin, 39(7), 870-882. https://doi.org/10.1177/0146167213483580

Farwell, L., \& Wohlwend-Lloyd, R. (1998). Narcissistic processes: Optimistic expectations, favorable self-evaluations, and self-enhancing attributions. Journal of Personality, 66(1), 65-83.

Festinger, L. (1954). A theory of social comparison processes. Human Relations, 7(2), 117-140.

Gabriel, M. T., Critelli, J. W., \& Ee, J. S. (1994). Narcissistic illusions in self-evaluations of intelligence and attractiveness. Journal of Personality, 62(1), 143-155.

Garcia, S. M., Tor, A., \& Schiff, T. M. (2013). The psychology of competition: A social comparison perspective. Perspectives on Psychological Science, 8(6), 634-650.

Gastorf, J., Suls, J., \& Lawhon, J. (1978). Opponent choices of below average performers. Bulletin of the Psychonomic Society, 12(3), 217-220.

Geniole, S. N., MacDonell, E. T., \& McCormick, C. M. (2017). The Point Subtraction Aggression Paradigm as a laboratory tool for investigating the neuroendocrinology of aggression and competition. Hormones and Behavior, 92, 103-116.

https://doi.org/10.1016/j.yhbeh.2016.04.006

Gilbert, P., McEwan, K., Bellew, R., Mills, A., \& Gale, C. (2009). The dark side of competition: How competitive behaviour and striving to avoid inferiority are linked to depression, anxiety, stress and self-harm. Psychology and Psychotherapy: Theory, Research and Practice, 82(2), 123-136. https://doi.org/10.1348/147608308X379806

Gilbert, P., Price, J., \& Allan, S. (1995). Social comparison, social attractiveness and evolution: How might they be related? New Ideas in Psychology, 13(2), 149-165.

Goldberg, L. R., Johnson, J. A., Eber, H. W., Hogan, R., Ashton, M. C., Cloninger, C. R., \& Gough, H. G. (2006). The international personality item pool and the future of publicdomain personality measures. Journal of Research in Personality, 40(1), 84-96.

Grapsas, S., Brummelman, E., Back, M. D., \& Denissen, J. J. A. (2020). The "Why" and "How" of Narcissism: A Process Model of Narcissistic Status Pursuit. Perspectives on Psychological Science, 15(1), 150-172. https://doi.org/10.1177/1745691619873350

Hamilton, M. (1960). A rating scale for depression. Journal of Neurology, Neurosurgery, and Psychiatry, 23(1), 56.

Henry, J. D., \& Crawford, J. R. (2005). The short-form version of the Depression Anxiety Stress Scales (DASS-21): Construct validity and normative data in a large non-clinical sample. British Journal of Clinical Psychology, 44(2), 227-239.

Hoffman, P. J., Festinger, L., \& Lawrence, D. H. (1954). Tendencies toward group comparability in competitive bargaining. Human Relations, 7(2), 141-159. 
Holtzman, N. S., \& Donnellan, M. B. (2015). The roots of Narcissus: Old and new models of the evolution of narcissism. In Evolutionary perspectives on social psychology (pp. 479-489). Springer.

Horton, R. S., \& Sedikides, C. (2009). Narcissistic responding to ego threat: When the status of the evaluator matters. Journal of Personality, 77(5), 1493-1526.

Johnson, S. L., Leedom, L. J., \& Muhtadie, L. (2012). The dominance behavioral system and psychopathology: Evidence from self-report, observational, and biological studies. Psychological Bulletin, 138(4), 692-743. https://doi.org/10.1037/a0027503

Kilduff, G. J., Elfenbein, H. A., \& Staw, B. M. (2010). The psychology of rivalry: A relationally dependent analysis of competition. Academy of Management Journal, 53(5), 943-969.

Krizan, Z., \& Bushman, B. J. (2011). Better than my loved ones: Social comparison tendencies among narcissists. Personality and Individual Differences, 50(2), 212-216. https://doi.org/10.1016/j.paid.2010.09.031

Larrieu, T., Cherix, A., Duque, A., Rodrigues, J., Lei, H., Gruetter, R., \& Sandi, C. (2017). Hierarchical status predicts behavioral vulnerability and nucleus accumbens metabolic profile following chronic social defeat stress. Current Biology, 27(14), 2202-2210.

Ligneul, R., Obeso, I., Ruff, C. C., \& Dreher, J.-C. (2016). Dynamical Representation of Dominance Relationships in the Human Rostromedial Prefrontal Cortex. Current Biology: CB, 26(23), 3107-3115. https://doi.org/10.1016/j.cub.2016.09.015

Lipsitz, J. D., \& Markowitz, J. C. (2013). Mechanisms of change in interpersonal therapy (IPT). Clinical Psychology Review, 33(8), 1134-1147. https://doi.org/10.1016/j.cpr.2013.09.002

Luchner, A. F., Houston, J. M., Walker, C., \& Alex Houston, M. (2011). Exploring the relationship between two forms of narcissism and competitiveness. Personality and Individual Differences, 51(6), 779-782. https://doi.org/10.1016/j.paid.2011.06.033

Mahadevan, N., Gregg, A. P., Sedikides, C., \& de Waal-Andrews, W. G. (2016). Winners, Losers, Insiders, and Outsiders: Comparing Hierometer and Sociometer Theories of SelfRegard. Frontiers in Psychology, 7. https://doi.org/10.3389/fpsyg.2016.00334

Morf, C. C., \& Rhodewalt, F. (2001). Unraveling the Paradoxes of Narcissism: A Dynamic SelfRegulatory Processing Model. Psychological Inquiry, 12(4), 177-196. https://doi.org/10.1207/S15327965PLI1204_1

O’Connor, L. E., Berry, J. W., Weiss, J., \& Gilbert, P. (2002). Guilt, fear, submission, and empathy in depression. Journal of Affective Disorders, 71(1), 19-27.

Pincus, A. L., Ansell, E. B., Pimentel, C. A., Cain, N. M., Wright, A. G. C., \& Levy, K. N. (2009). Initial construction and validation of the Pathological Narcissism Inventory. Psychological Assessment, 21(3), 365-379. https://doi.org/10.1037/a0016530

Pincus, A. L., Cain, N. M., \& Wright, A. G. (2014). Narcissistic grandiosity and narcissistic vulnerability in psychotherapy. Personality Disorders: Theory, Research, and Treatment, 5(4), 439-443.

Price, J., Sloman, L., Gardner, R., Gilbert, P., \& Rohde, P. (1994). The social competition hypothesis of depression. The British Journal of Psychiatry, 164(3), 309-315.

Reuderink, B., Nijholt, A., \& Poel, M. (2009). Affective Pacman: A Frustrating Game for BrainComputer Interface Experiments. In A. Nijholt, D. Reidsma, \& H. Hondorp (Eds.), Intelligent Technologies for Interactive Entertainment (Vol. 9, pp. 221-227). Springer Berlin Heidelberg. https://doi.org/10.1007/978-3-642-02315-6_23 
Rhodewalt, F., \& Morf, C. C. (1998). On self-aggrandizement and anger: A temporal analysis of narcissism and affective reactions to success and failure. Journal of Personality and Social Psychology, 74(3), 672.

Safran, J. D., \& Greenberg, L. S. (1988). Feeling, thinking, and acting: A cognitive framework for psychotherapy integration. Journal of Cognitive Psychotherapy, 2(2), 109-131.

Schoenleber, M., Roche, M. J., Wetzel, E., Pincus, A. L., \& Roberts, B. W. (2015). Development of a brief version of the Pathological Narcissism Inventory. Psychological Assessment, 27(4), 1520.

Sherman, E. D., Miller, J. D., Few, L. R., Campbell, W. K., Widiger, T. A., Crego, C., \& Lynam, D. R. (2015). Development of a Short Form of the Five-Factor Narcissism Inventory: The FFNI-SF. Psychological Assessment, 27(3), 1110-1116. https://doi.org/10.1037/pas0000100

Sideridis, G. D. (2005). Goal Orientation, Academic Achievement, and Depression: Evidence in Favor of a Revised Goal Theory Framework. Journal of Educational Psychology, 97(3), 366-375. https://doi.org/10.1037/0022-0663.97.3.366

Sivanathan, N., \& Pettit, N. C. (2010). Protecting the self through consumption: Status goods as affirmational commodities. Journal of Experimental Social Psychology, 46(3), 564-570. https://doi.org/10.1016/j.jesp.2010.01.006

Sullivan, H. S. (1953). The interpersonal theory of psychiatry. Journal of Consulting Psychology, 17(5), 401.

Szanto, K., Bruine de Bruin, W., Parker, A. M., Hallquist, M. N., Vanyukov, P. M., \& Dombrovski, A. Y. (2015). Decision-making competence and attempted suicide. The Journal of Clinical Psychiatry, 76(12), e1590-1597. https://doi.org/10.4088/JCP.15m09778

Venzala, E., García-García, A. L., Elizalde, N., Delagrange, P., \& Tordera, R. M. (2012). Chronic social defeat stress model: Behavioral features, antidepressant action, and interaction with biological risk factors. Psychopharmacology, 224(2), 313-325. https://doi.org/10.1007/s00213-012-2754-5

White, J. B., \& Langer, E. J. (1999). Horizontal hostility; Relations between similar minority groups. Journal of Social Issues, 55(3), 537-559.

Wright, A. G., Stepp, S. D., Scott, L. N., Hallquist, M. N., Beeney, J. E., Lazarus, S. A., \& Pilkonis, P. A. (2017). The effect of pathological narcissism on interpersonal and affective processes in social interactions. Journal of Abnormal Psychology, 126(7), 898.

Zeigler-Hill, V., McCabe, G. A., Vrabel, J. K., Raby, C. M., \& Cronin, S. (2018). The Narcissistic Pursuit of Status. In A. D. Hermann, A. B. Brunell, \& J. D. Foster (Eds.), Handbook of Trait Narcissism (pp. 299-306). Springer International Publishing. https://doi.org/10.1007/978-3-319-92171-6_32

Zeigler-Hill, V., Vrabel, J. K., McCabe, G. A., Cosby, C. A., Traeder, C. K., Hobbs, K. A., \& Southard, A. C. (2019). Narcissism and the pursuit of status. Journal of Personality, 87(2), 310-327. https://doi.org/10.1111/jopy.12392 


\section{Supplemental Material}

\begin{tabular}{|c|c|c|c|c|}
\hline & \multirow{2}{*}{ Sample 1} & \multicolumn{3}{|c|}{ Sample 2} \\
\hline & & TOTAL & healthy & depressed \\
\hline $\mathrm{n}$ & 70 & 85 & 25 & 60 \\
\hline Age (mean (sd)) & $21.46(3.34)$ & $62.62(7.98)$ & $65.04(8.92)$ & $61.62(7.39)$ \\
\hline Female sex (\%) & $55(78.6)$ & $51(60.0)$ & $16(64.0)$ & $35(58.3)$ \\
\hline \multicolumn{5}{|l|}{ Race (\%) } \\
\hline Caucasian & $14(20.9)$ & $68(80.0)$ & $23(92.0)$ & $45(75.0)$ \\
\hline Asian & $39(58.2)$ & $2(2.4)$ & $0(-)$ & $2(3.3)$ \\
\hline African-American/African-Canadian & $1(1.5)$ & $14(16.5)$ & $2(10.0)$ & $12(20.0)$ \\
\hline Other & $13(19.4)$ & $1(1.2)$ & $0(-)$ & $1(1.7)$ \\
\hline Household income in USD (mean (sd)) & --- & $\begin{array}{c}43,148.81 \\
(31,212.52)\end{array}$ & $\begin{array}{l}64,020.00 \\
(28399.12) \\
\end{array}$ & $\begin{array}{l}34,305.08 \\
(28161.94)\end{array}$ \\
\hline \multicolumn{5}{|l|}{ Household income in CAD (\%) } \\
\hline$<25,000$ & $6(9.0)$ & ---- & ---- & ---- \\
\hline $25,000-49,999$ & $10(14.9)$ & $\begin{array}{cc}--- \\
\end{array}$ & $\begin{array}{c}--- \\
\end{array}$ & $\begin{array}{c}--- \\
\end{array}$ \\
\hline $50,000-74,999$ & $13(19.4)$ & $\begin{array}{cc}--- \\
\end{array}$ & $\begin{array}{cc}--- \\
\end{array}$ & $\begin{array}{cc}--- \\
\end{array}$ \\
\hline $75,000-99,999$ & $15(22.4)$ & ---- & ---- & ---- \\
\hline $100,000-149,999$ & $12(17.9)$ & ---- & ---- & ---- \\
\hline$\geq 150,000$ & $11(16.4)$ & $\begin{array}{cc}--- \\
\end{array}$ & $\begin{array}{cc}--- \\
\end{array}$ & $\begin{array}{c}--- \\
\end{array}$ \\
\hline Game experience (mean (sd)) & $1.79(1.30)$ & $2.55(1.51)$ & $2.68(1.44)$ & $2.50(1.55)$ \\
\hline DASS-21 depression subscale (mean (sd)) & $9.51(8.86)$ & ---- & ---- & ---- \\
\hline HRSD (mean (sd)) & ---- & $12.14(9.03)$ & $1.80(1.96)$ & $16.45(7.09)$ \\
\hline $\begin{array}{l}\text { Depression severity percentile based on } \\
\text { general population norms }{ }^{*}(\text { mean }(\mathrm{sd}))\end{array}$ & $59.46(24.93)$ & $62.51(34.11)$ & $17.60(16.82)$ & $81.22(18.18)$ \\
\hline FFNI total score (mean $(\mathrm{sd}))$ & $\begin{array}{l}153.21 \\
(28.16)\end{array}$ & $\begin{array}{l}134.36 \\
(25.49)\end{array}$ & $\begin{array}{l}127.68 \\
(17.77)\end{array}$ & $\begin{array}{l}137.34 \\
(27.90) \\
\end{array}$ \\
\hline IPIP-DS total score (mean (sd)) & ---- & $26.49(8.08)$ & $28.00(6.39)$ & $25.82(8.70)$ \\
\hline
\end{tabular}

Supplemental Table S1: Characteristics of Sample 1 and 2. ${ }^{*}$ See Methods - Statistical analysis for a description of how depression percentile norms were obtained. 

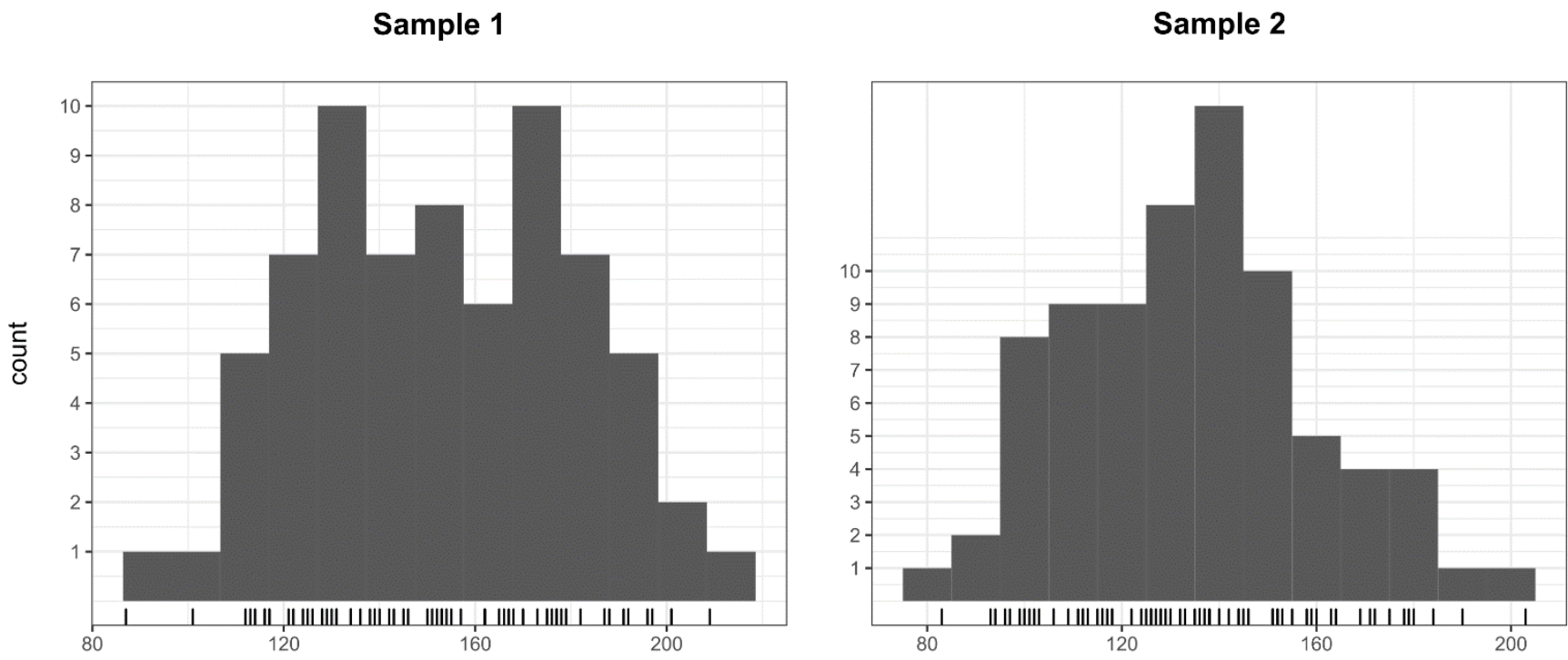

FFNI total score

Supplemental Figure S1: Distribution of narcissistic scores in the two samples. FFNI, Five-Factor Narcissism Inventory (scoring range: 60-300).

\begin{tabular}{|c|c|c|c|}
\hline \multirow{2}{*}{ Measured construct } & \multirow{2}{*}{ Scale } & Sample 1 & Sample 2 \\
\hline & & \multicolumn{2}{|c|}{ Cronbach's a } \\
\hline Trait dominance & IPIP-DS & Scale not collected & .84 \\
\hline \multirow{9}{*}{ Narcissism } & FFNI & .92 & .90 \\
\hline & Grandiosity & .93 & .88 \\
\hline & Vulnerability & .81 & .91 \\
\hline & Agentic Extraversion & .88 & .85 \\
\hline & Antagonism & .92 & .89 \\
\hline & Narcissistic Neuroticism & .86 & .90 \\
\hline & BPNI & .92 & .95 \\
\hline & Grandiosity & .86 & .88 \\
\hline & Vulnerability & .89 & .94 \\
\hline \multirow{2}{*}{ Depression } & DASS-21 depression & .88 & Scale not collected \\
\hline & HRSD & Scale not collected & .89 \\
\hline
\end{tabular}

Supplemental Table S2: Reliability of psychometric measures used in the study. Legend: IPIP-DS, International Personality Item Pool Dominance Subscale; FFNI, Five-Factor Narcissism Inventory; BPNI, Brief Pathological Narcissism Inventory; HRSD, Hamilton Rating Scale for Depression. 


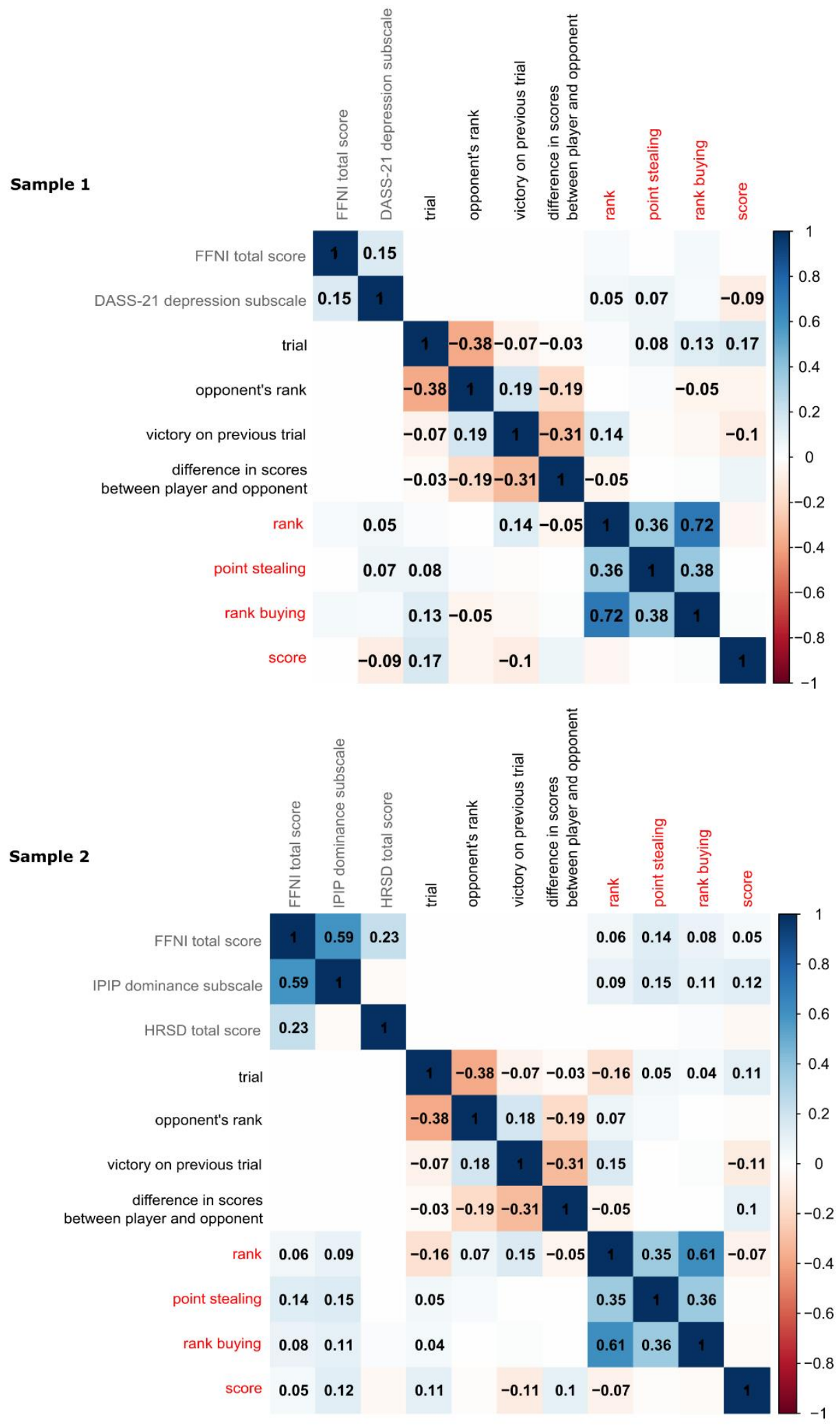

Supplemental Figure S2: Spearman correlations between psychometric and task-related variables. In grey: psychometric variables, in black: preset design variables (uniform for all participants), in red: behavior-dependent variables. Numbers indicate coefficients of significant correlations $(p<.05)$. Legend: FFNI, Five-Factor Narcissism Inventory; HRSD, Hamilton Rating Scale for Depression; * $p<.05 ;{ }^{* *}, p<.01$; ***, $p<.001$. 
Sample 1

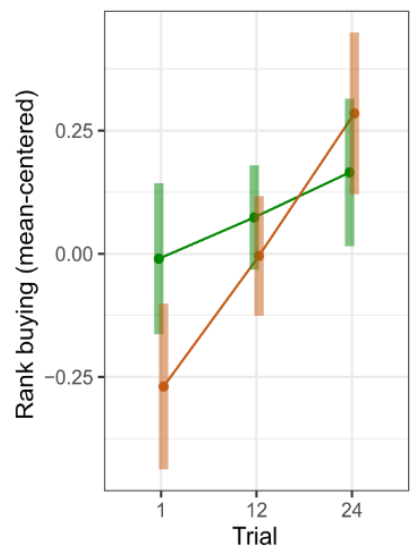

FFNI: $+125($ mean - 1 SD) $-181($ mean +1 SD)
Sample 2
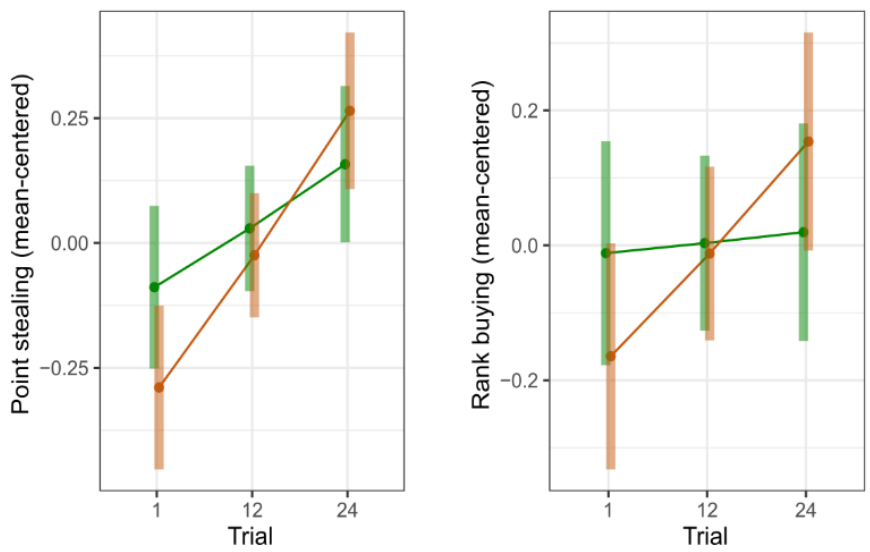

FFNI: - $109($ mean $-1 \mathrm{SD})+160($ mean $+1 \mathrm{SD})$

Panel B: Depression*opponent's rank effect in Samples 1 and 2

Sample 1

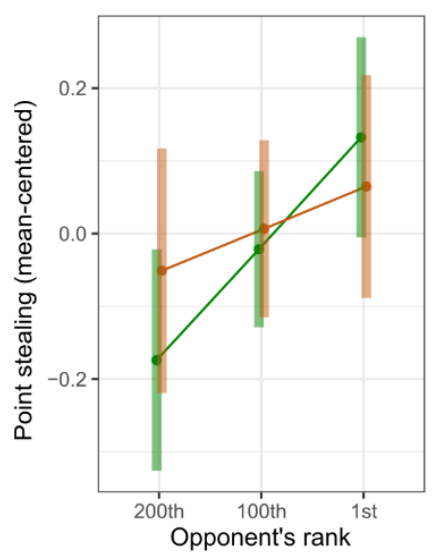

DASS-21 depression subscale:

$+1($ mean $-1 \mathrm{SD})+18($ mean $+1 \mathrm{SD})$
Sample 2

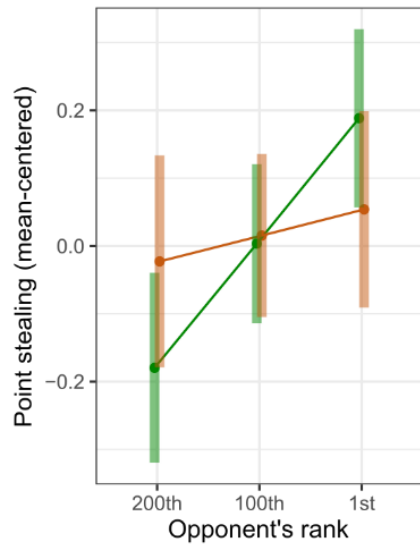

HRSD:

$\leftarrow 9($ mean $-1 \mathrm{SD})+22($ mean $+1 \mathrm{SD})$
Panel C: Depression*opponent's rank effect with depression analyzed categorically (Sample 2)

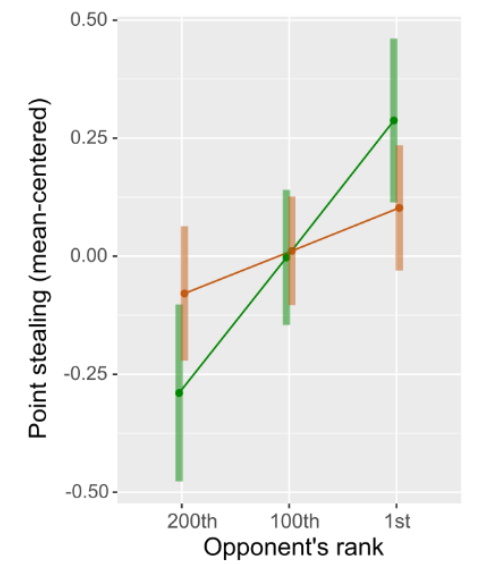

- non-depressed (HRSD < 14) + depressed (HRSD $\geq 14)$

Supplemental Figure S3, Panel A: Narcissismtrial effects in the individual samples, indicating a steeper increase of point stealing and rank buying over time in more narcissistic participants. The narcissism*trial effect predicting point stealing was not significant in Sample 1 (not shown), the other effects are consistent in their pattern and direction. Panel B: Depression*opponent's rank effect predicting point stealing in the individual samples, indicating that more depressed individuals tended to steal points indiscriminately of their opponent's rank. The effect had a consistent pattern across samples but did not survive the inclusion of covariates in Sample 1 (plots shown in figure were generated from models including covariates). Panel C: The depression*opponent's rank effect predicting point stealing remained significant when depression was analyzed categorically in Sample 2. Points indicate estimates and vertical bars 95\% confidence intervals. Legend: FFNI, Five-Factor Narcissism Inventory; HRSD, Hamilton Rating Scale for Depression. 

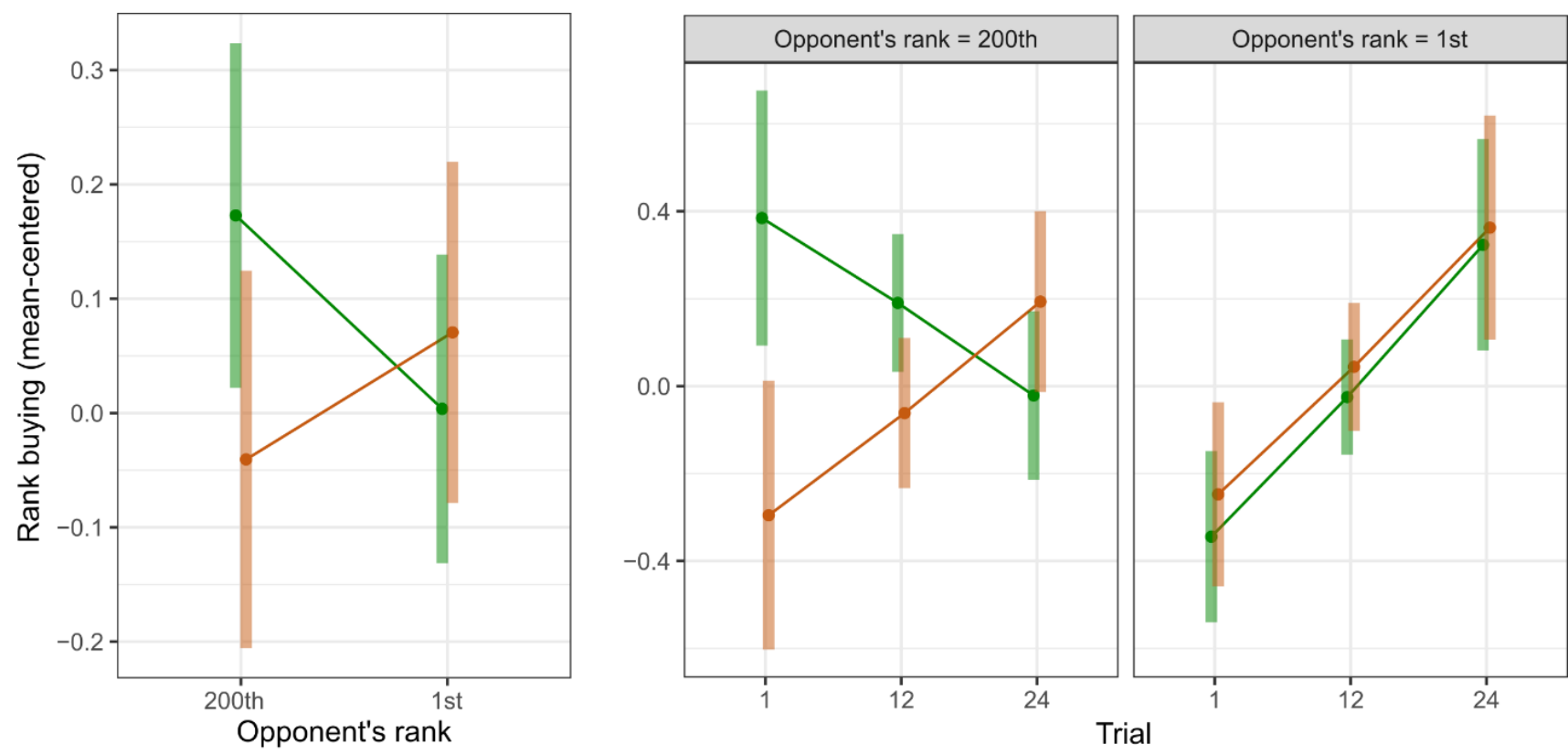

FFNI: 125 (mean - 1 SD) $181($ mean + 1 SD)

Supplemental Figure S4, Narcissism*opponent's rank (left) and narcissism*opponent's rank trial effects (right) predicting rank buying in Sample 1, indicating that although more narcissistic participants bought rank preferentially against high-ranked opponents, they also increased rank buying against lowranked opponents over time. Less narcissistic individuals had an opposite tendencies, buying rank preferentially against low-ranked opponents, but decreasing rank buying against them with time. These effects were significant neither in Sample 2 nor in the pooled analysis, and thus were not retained as main findings. Points indicate estimates and vertical bars $95 \%$ confidence intervals. Legend: FFNI, Five-Factor Narcissism Inventory. 


\section{Sensitivity analyses}

\section{(a) Stereotypical responding}

\begin{tabular}{|c|c|c|}
\hline & Sample 1 (N = 70) & Sample 2 (N = 85) \\
\hline Point stealing & $15 / 70(21 \%)$ & $18 / 85(21 \%)$ \\
\hline Rank buying & $13 / 70(19 \%)$ & $15 / 85(18 \%)$ \\
\hline Both measures & $9 / 70(13 \%)$ & $10 / 85(12 \%)$ \\
\hline
\end{tabular}

Supplemental Table S3. Stereotypical response rates per sample and outcome variable. Rates were comparable between the two samples and did not exceed $13 \%$ of participants in total.

\begin{tabular}{|c|c|c|c|c|c|c|}
\hline & \multicolumn{3}{|c|}{ Sample 1} & \multicolumn{3}{|c|}{ Sample 2} \\
\hline & $\begin{array}{l}\text { Stereotypical } \\
\text { responders }\end{array}$ & $\begin{array}{c}\text { Other } \\
\text { participants }\end{array}$ & $p$ & $\begin{array}{l}\text { Stereotypical } \\
\text { responders }\end{array}$ & $\begin{array}{c}\text { Other } \\
\text { participants }\end{array}$ & $p$ \\
\hline $\mathrm{n}$ & 9 & 61 & ---- & 10 & 75 & ---- \\
\hline Age (mean (sd)) & $20.78(1.56)$ & $21.56(3.53)$ & 0.518 & $63.40(8.30)$ & $62.52(7.98)$ & 0.745 \\
\hline Female sex (\%) & $8(88.9)$ & $47(77.0)$ & 0.709 & $4(40.0)$ & $47(62.7)$ & 0.303 \\
\hline Race (\%) & & & 0.974 & & & 0.021 \\
\hline Caucasian & $2(22.2)$ & $12(20.7)$ & & $9(90.0)$ & $59(78.7)$ & \\
\hline Asian & $5(55.6)$ & $34(58.6)$ & & $0(0.0)$ & $2(2.7)$ & \\
\hline African-American/-Canadian & $0(0.0)$ & $1(1.7)$ & & $0(0.0)$ & $14(18.7)$ & \\
\hline Other & $2(22.2)$ & $11(19.0)$ & & $1(10.0)$ & $0(0.0)$ & \\
\hline $\begin{array}{l}\text { Household income in USD } \\
\text { (mean (sd)) }\end{array}$ & ---- & ---- & ---- & $\begin{array}{c}50800.00 \\
(34892.06)\end{array}$ & $\begin{array}{c}42114.86 \\
(30797.34)\end{array}$ & 0.412 \\
\hline Household income in CAD (\%) & & & 0.925 & ---- & ---- & $\begin{array}{c}--- \\
\end{array}$ \\
\hline$<25,000$ & $0(0.0)$ & $6(10.3)$ & & & & \\
\hline $25,000-49,999$ & $1(11.1)$ & $9(15.5)$ & & & & \\
\hline $50,000-74,999$ & $2(22.2)$ & $11(19.0)$ & & & & \\
\hline 75,000 - 99,999 & $2(22.2)$ & $13(22.4)$ & & & & \\
\hline $100,000-149,999$ & $2(22.2)$ & $10(17.2)$ & & & & \\
\hline$\geq 150,000$ & $2(22.2)$ & $9(15.5)$ & & & & \\
\hline Game experience (mean (sd)) & $2.11(1.69)$ & $1.74(1.24)$ & 0.424 & $2.70(1.83)$ & $2.53(1.47)$ & 0.745 \\
\hline $\begin{array}{l}\text { DASS-21 depression subscale } \\
\text { (mean (sd)) }\end{array}$ & $4.44(5.17)$ & $4.80(4.35)$ & 0.822 & ---- & ---- & ---- \\
\hline HRSD (mean (sd)) & $\begin{array}{c}--- \\
--1\end{array}$ & ---- & $\begin{array}{c}--- \\
\end{array}$ & $12.67(7.70)$ & $16.02(6.09)$ & 0.149 \\
\hline FFNI total score (mean (sd)) & $\begin{array}{l}155.44 \\
(30.70)\end{array}$ & $\begin{array}{l}152.89 \\
(28.03)\end{array}$ & 0.801 & $\begin{array}{l}131.56 \\
(32.11)\end{array}$ & $\begin{array}{l}134.71 \\
(24.80)\end{array}$ & 0.729 \\
\hline IPIP-DS total score (mean (sd)) & ---- & ---- & $\begin{array}{ll}--- \\
\end{array}$ & $25.56(10.91)$ & $26.61(7.75)$ & 0.714 \\
\hline
\end{tabular}

Supplemental Table S4. Stereotypical responders did not differ significantly from other participants on demographic and psychometric measures, with the sole exception of race in Sample 2. 


\begin{tabular}{|c|c|c|c|}
\hline \multirow[t]{2}{*}{$\begin{array}{l}\text { Main findings retested after exclusion of } \\
\text { stereotypical responders }\end{array}$} & $\begin{array}{c}\text { Reduced } \\
\text { Sample } 1 \\
(\mathbf{N}=61) \\
\end{array}$ & $\begin{array}{c}\text { Reduced } \\
\text { Sample } 2 \\
(\mathrm{~N}=75) \\
\end{array}$ & $\begin{array}{l}\text { Pooled } \\
(N=136)\end{array}$ \\
\hline & \multicolumn{3}{|c|}{ Coefficient (standard error) } \\
\hline \multicolumn{4}{|c|}{ (i) Reaction to defeat } \\
\hline \multicolumn{4}{|c|}{ Point stealing } \\
\hline Point stealing increases over time & $.151(.031)^{\star \star \star}$ & $.131(.042)^{\star \star \star}$ & $.144(.020)^{\star \star \star}$ \\
\hline $\begin{array}{l}\text { Point stealing increases more over time in participants } \\
\text { with higher levels of trait dominance }\end{array}$ & $\begin{array}{l}\text { scale not } \\
\text { collected }\end{array}$ & $.073(.026)^{\star \star}$ & - \\
\hline $\begin{array}{l}\text { Point stealing increases more over time in participants } \\
\text { with higher levels of narcissism }\end{array}$ & $.034(.026)$ & $.054(.023)^{\star}$ & $.052(.017)^{\star \star}$ \\
\hline \multicolumn{4}{|c|}{ Rank buying } \\
\hline Rank buying increases over time & $.120(.029)^{\star \star \star}$ & $.051(.026)^{\star}$ & $.084(.019)^{\star \star \star}$ \\
\hline $\begin{array}{l}\text { Rank buying increases more over time in participants } \\
\text { with higher levels of trait dominance }\end{array}$ & $\begin{array}{l}\text { scale not } \\
\text { collected }\end{array}$ & $.060(.024)^{\star}$ & - \\
\hline $\begin{array}{l}\text { Rank buying increases more over time in participants } \\
\text { with higher levels of narcissism }\end{array}$ & $.069(.028)^{\star}$ & $.049(.023)^{*}$ & $.061(.017)^{\star \star \star}$ \\
\hline \multicolumn{4}{|c|}{ (ii) Level of social comparisons } \\
\hline \multicolumn{4}{|c|}{ Point stealing } \\
\hline Point stealing increases against high-ranked opponents & $.079(.028)^{\star \star}$ & $.108(.024)^{\star \star \star}$ & $.097(.018)^{\star \star \star}$ \\
\hline $\begin{array}{l}\text { Point stealing increases more against high-ranked } \\
\text { opponents after having performed well on the arcade } \\
\text { game }\end{array}$ & $.053(.024)^{\star}$ & $.059(.022)^{\star \star}$ & $.038(.016)^{\star}$ \\
\hline $\begin{array}{l}\text { Point stealing increases against high-ranked opponents } \\
\text { in participants with higher levels of trait dominance }\end{array}$ & $\begin{array}{l}\text { scale not } \\
\text { collected }\end{array}$ & $.081(.024)^{\star \star \star}$ & - \\
\hline $\begin{array}{l}\text { Point stealing does not increase against high-ranked } \\
\text { opponents in highly depressed participants }\end{array}$ & $-.040(.028)$ & $-.073(.021)^{\star \star \star}$ & $.067(.016)^{\star \star \star}$ \\
\hline \multicolumn{4}{|c|}{ Rank buying } \\
\hline $\begin{array}{l}\text { Rank buying increases more over time against high- } \\
\text { ranked opponents }\end{array}$ & $.067(.024)^{\star \star}$ & $.008(.022)$ & $.034(.017)^{\star}$ \\
\hline
\end{tabular}

Supplemental Table S5: Sensitivity analysis of main findings after exclusion of participants with stereotypical responses on both point stealing and rank buying. Significant effects are in bold. All main findings remained significant in the reduced samples. Legend: ${ }^{*}, p<.05 ;{ }^{* *}, p<.01 ;{ }^{* *}, p<.001$. 


\section{(b) Effects of sex}

\begin{tabular}{|c|c|c|c|}
\hline \multirow{2}{*}{$\begin{array}{l}\text { Main findings retested in models covarying for } \\
\text { sex*trial, sex*outcome and sex*opponent's rank }\end{array}$} & $\begin{array}{c}\text { Sample } 1 \\
(\mathrm{~N}=70)\end{array}$ & $\begin{array}{c}\text { Sample } 2 \\
(\mathrm{~N}=85)\end{array}$ & $\begin{array}{l}\text { Pooled } \\
(\mathrm{N}=155)\end{array}$ \\
\hline & \multicolumn{3}{|c|}{ Coefficient (standard error) } \\
\hline \multicolumn{4}{|c|}{ (i) Reaction to defeat } \\
\hline \multicolumn{4}{|c|}{ Point stealing } \\
\hline Point stealing increases over time & $.126(.029)^{\star \star \star}$ & $.118(.029)^{\star \star \star}$ & $.127(.020)^{\star \star \star}$ \\
\hline $\begin{array}{l}\text { Point stealing increases more over time in participants } \\
\text { with higher levels of trait dominance }\end{array}$ & $\begin{array}{l}\text { scale not } \\
\text { collected }\end{array}$ & $.066(.023)^{\star \star}$ & - \\
\hline $\begin{array}{l}\text { Point stealing increases more over time in participants } \\
\text { with higher levels of narcissism }\end{array}$ & $.025(.022)$ & $.054(.021)^{\star}$ & $.044(.015)^{\star \star}$ \\
\hline \multicolumn{4}{|c|}{ Rank buying } \\
\hline Rank buying increases over time & $.125(.028)^{\star \star \star}$ & $.047(.029)$ & $.089(.020)^{\star \star \star}$ \\
\hline $\begin{array}{l}\text { Rank buying increases more over time in participants with } \\
\text { higher levels of trait dominance }\end{array}$ & $\begin{array}{l}\text { scale not } \\
\text { collected }\end{array}$ & $.057(.022)^{\star \star}$ & \\
\hline $\begin{array}{l}\text { Rank buying increases more over time in participants with } \\
\text { higher levels of narcissism }\end{array}$ & $.060(.024)^{\star}$ & $.053(.022)^{\star}$ & $.057(.015)^{\star \star \star}$ \\
\hline \multicolumn{4}{|c|}{ (ii) Level of social comparisons } \\
\hline \multicolumn{4}{|c|}{ Point stealing } \\
\hline Point stealing increases against high-ranked opponents & $.078(.027)^{\star \star}$ & $.089(.027)^{\star \star}$ & $.080(.019)^{\star \star \star}$ \\
\hline $\begin{array}{l}\text { Point stealing increases more against high-ranked } \\
\text { opponents after having performed well on the arcade } \\
\text { game }\end{array}$ & $.056(.023)^{\star}$ & $.049(.019)^{\star}$ & $.031(.014)^{\star}$ \\
\hline $\begin{array}{l}\text { Point stealing increases against high-ranked opponents in } \\
\text { participants with higher levels of trait dominance }\end{array}$ & $\begin{array}{l}\text { scale not } \\
\text { collected }\end{array}$ & $.071(.022)^{\star \star}$ & - \\
\hline $\begin{array}{l}\text { Point stealing does not increase against high-ranked } \\
\text { opponents in highly depressed participants }\end{array}$ & $-.032(.024)$ & $-.064(0.19)^{\star \star \star}$ & $-.057(.014)^{\star \star \star}$ \\
\hline \multicolumn{4}{|c|}{ Rank buying } \\
\hline $\begin{array}{l}\text { Rank buying increases more over time against high- } \\
\text { ranked opponents }\end{array}$ & $.059(.021)^{\star \star}$ & $.008(.020)$ & $.030(.014)^{\star}$ \\
\hline
\end{tabular}

Supplemental Table S6: Sensitivity analysis of main findings covarying for sex*trial, sex*outcome and sex*opponent's rank. Significant effects are in bold. All effects were robust to the additional covariates, with the exception of the main effect of trial predicting rank buying in Sample 2 (highlighted in yellow), which nevertheless maintained a similar effect magnitude as in the principal model. Coefficients were computed with female sex as the reference group. Legend: ${ }^{*}, p<.05 ;{ }^{* *}, p<.01 ;{ }^{* * *}, p<.001$. 


\begin{tabular}{|c|c|c|c|}
\hline \multirow{2}{*}{ Effects tested } & Sample 1 & Sample 2 & Pooled \\
\hline & \multicolumn{3}{|c|}{ Coefficients (standard error) } \\
\hline \multicolumn{4}{|c|}{ Point stealing } \\
\hline Male sex*trial & $.047(.054)$ & $-.019(.041)$ & $-.010(.032)$ \\
\hline Male sex*trait dominance*trial & scale not collected & $.070(.043)$ & - \\
\hline Male sex*narcissismtrial & $-.005(.053)$ & $-.038(.043)$ & $-.007(.033)$ \\
\hline Male sex*opponent's rank & $-.056(.055)$ & $.027(.039)$ & $.023(.030)$ \\
\hline Male sex*opponent's rank*previous score & $-.057(.049)$ & $.012(.039)$ & $-.037(.028)$ \\
\hline Male sex*trait dominance*opponent's rank & scale not collected & $-.055(.040)$ & - \\
\hline Male sex*depression*opponent's rank & $.001(.069)$ & $.046(.040)$ & $.049(.030)$ \\
\hline \multicolumn{4}{|c|}{ Rank buying } \\
\hline Male sex*trial & $-.138(.051)^{\star \star}$ & $-.034(.042)$ & $-.083(.032)^{\star \star}$ \\
\hline Male sex*trait dominance*trial & scale not collected & $.069(.044)$ & - \\
\hline Male sex*narcissismtrial & $-.095(.051)$ & $.003(.044)$ & $-.049(.033)$ \\
\hline Male sex*opponent's rank*trial & $-.070(.050)$ & $-.088(.040)^{\star}$ & $-.087(.031)^{\star \star}$ \\
\hline
\end{tabular}

Supplemental Table S7: Main findings tested for moderation by sex. Significant effects are in bold. Sex interacted with trial and opponent's rank*trial effects predicting rank buying. Sex did not moderate any of our main findings involving trait dominance, narcissism or depression. Legend: ${ }^{*}, p<.05 ;{ }^{* *}, p<.01$. 


\section{Exploratory analyses}

\section{(b) Performance on the snake arcade game}

As in the main text, we primarily report findings in terms of the pooled analysis but detail discrepancies between samples (Supplemental Figure S5).

Trials had a significant main effect $\left(X^{2}{ }_{1}=104.95, p<.001\right)$. Younger age $\left(X^{2}{ }_{1}=133.71, p<.001\right)$, male sex $\left(x^{2}{ }_{1}=39.48, p<.001\right)$, having lost on the previous trial $\left(x^{2}{ }_{1}=65.76, p<.001\right)$, being pitted against a highranked opponent $\left(X^{2}{ }_{1}=8.89, p=.003\right)$, game experience $\left(X^{2}{ }_{1}=10.78, p=.001\right)$ and being Caucasian vs. Asian $\left(X^{2}{ }_{3}=8.86, p=.031\right)$ also predicted better performance. In Sample 1, opponents' rank did not influence scores significantly, whereas in Sample 2, game experience and race did not show significant main effects.
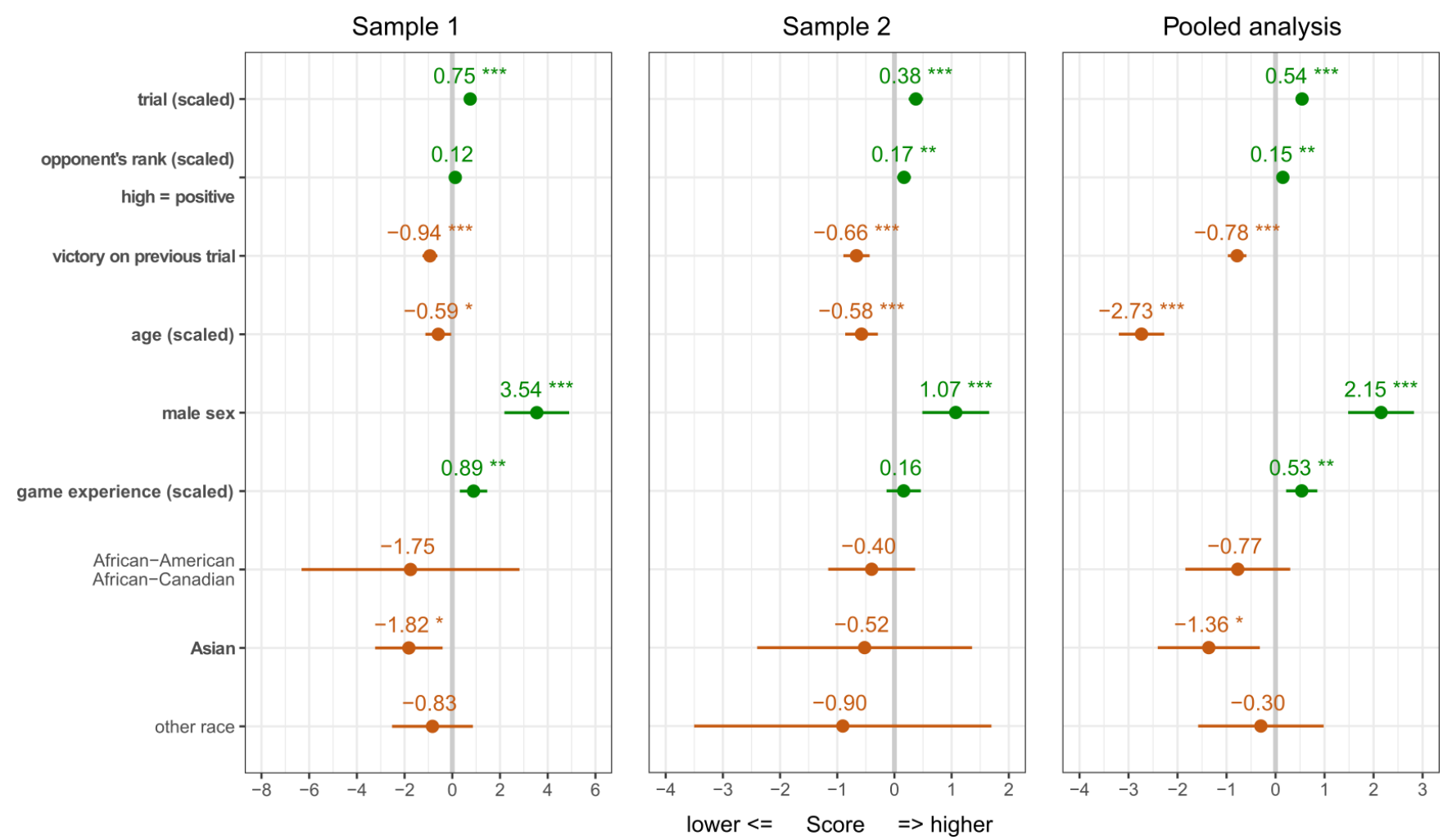

Supplemental Figure S5: Linear regression models predicting scores (task performance) in the two samples and the pooled analysis. Levels of race are compared to Caucasian. Effects significant in the pooled analysis are in bold. Points and numbers indicate estimates of fixed effects (negative estimates are displayed in orange); horizontal bars represent standard errors. Legend: ${ }^{*}, p<.05 ;{ }^{* *}, p<.01 ;{ }^{* * *}, p<.001$. 
In the pooled analysis, sample was added to all independent variables as an interaction term, after removing age from the model to avoid multicollinearity. Here, significant sample ${ }^{*}$ trial $\left(x^{2} 1=12.44, p<.001\right)$, sample* $\operatorname{sex}\left(X^{2}{ }_{1}=11.34, p<.001\right)$ and sample*game experience $\left(X^{2}{ }_{1}=4.22, p<.040\right)$ effects emerged, indicating that participants' scores in Sample 1 were overall higher and more steeply improving than in Sample 2, and that the difference in performance was larger in Sample 1 for men compared to women and for more experienced participants compared to less experienced ones (Figure S6, Panel A).

Last, trait dominance*trial, narcissism*trial and depression*trial effects were tested in the initial model (in Sample 2 for trait dominance and in pooled models for narcissism and depression; Supplemental Table S8 and Supplemental Figure S6, Panel B). Significant trait dominance ${ }^{*}$ trial $\left(x^{2}{ }_{1}=6.67, p=.010\right)$ and a narcissism ${ }^{*}$ trial effects $\left(X^{2}{ }_{1}=7.65, p=.006\right)$ suggested a higher task engagement in participants high on these traits. With respect to narcissistic subscales (Supplemental Table S8), the effect was driven by grandiosity as measured by both the FFNI and the BPNI (resp. $X^{2}{ }_{1}=10.34, p=.001$ and $X^{2}{ }_{1}=7.50, p=$ .006), and in the FFNI's three-factor subdivision, by agentic extraversion $\left(X^{2}{ }_{1}=8.98, p=.003\right)$ and to a lesser extent by antagonism $\left(X^{2}{ }_{1}=4.12, p=.042\right)$. Antagonism nevertheless predicted lower scores overall $\left(X^{2}{ }_{1}=4.37, p=.037\right.$ ), similarly to FFNI and BPNI vulnerability subscales (resp. $X^{2}{ }_{1}=6.85, p=.009$ and $X^{2}{ }_{1}$ $=10.02, p=.002)$. Depression also had a negative main effect $\left(X^{2}{ }_{1}=4.53, p=.033\right)$, but did not influence performance over time $\left(X^{2}{ }_{1}=.17, p=.677\right)$.

\begin{tabular}{|c|c|c|}
\hline \multirow{2}{*}{ Outcome variable: score } & Main effect & Psychometric measure*trial \\
\hline & \multicolumn{2}{|c|}{ Coefficient (standard error) } \\
\hline TRAIT DOMINANCE (Sample 2) & $.077(.160)$ & $.153(.059)^{\star \star}$ \\
\hline FFNI TOTAL SCORE & $-.331(.175)$ & $.135(.049)^{\star \star}$ \\
\hline FFNI Grandiosity & $-.150(.173)$ & $.155(.048)^{\star \star}$ \\
\hline FFNI Vulnerability & $-.427(.163)^{\star \star}$ & $.013(.049)$ \\
\hline FFNI Agentic extraversion & $-.002(.170)$ & $.146(.049)^{\star \star}$ \\
\hline FFNI Antagonism & $-.357(.171)^{\star}$ & $.098(.048)^{\star}$ \\
\hline FFNI Narcissistic neuroticism & $-.119(.166)$ & $-.008(.049)$ \\
\hline BPNI TOTAL SCORE & $-.487(.176)^{\star \star}$ & $.086(.050)$ \\
\hline BPNI Grandiosity & $-.296(.186)$ & $.134(.049)^{\star \star}$ \\
\hline BPNI Vulnerability & $-.528(.167)^{\star \star}$ & $.037(.050)$ \\
\hline DEPRESSION & $-.331(.156)^{\star}$ & $-.020(.048)$ \\
\hline
\end{tabular}

Supplemental Table S8: Psychometric measures predicting task performance in the pooled analysis (with the exception of trait dominance, only measured in Sample 2). Significant effects are in bold. Trait dominance, FFNI narcissism, both FFNI and BPNI grandiosity subscales and FFNI antagonism predicted a greater improvement in task performance over time (positive interaction with trial). Depression, BPNI narcissism, both FFNI and BPNI vulnerability subscales and FFNI antagonism predicted a poorer overall performance (significant main effect). Legend: FFNI, Five-Factor Narcissism Inventory; BPNI, Brief Pathological Narcissism Inventory; ${ }^{*}, p<.05 ;{ }^{* *}, p<.01$. 
Panel A: Differences between samples (pooled analysis)
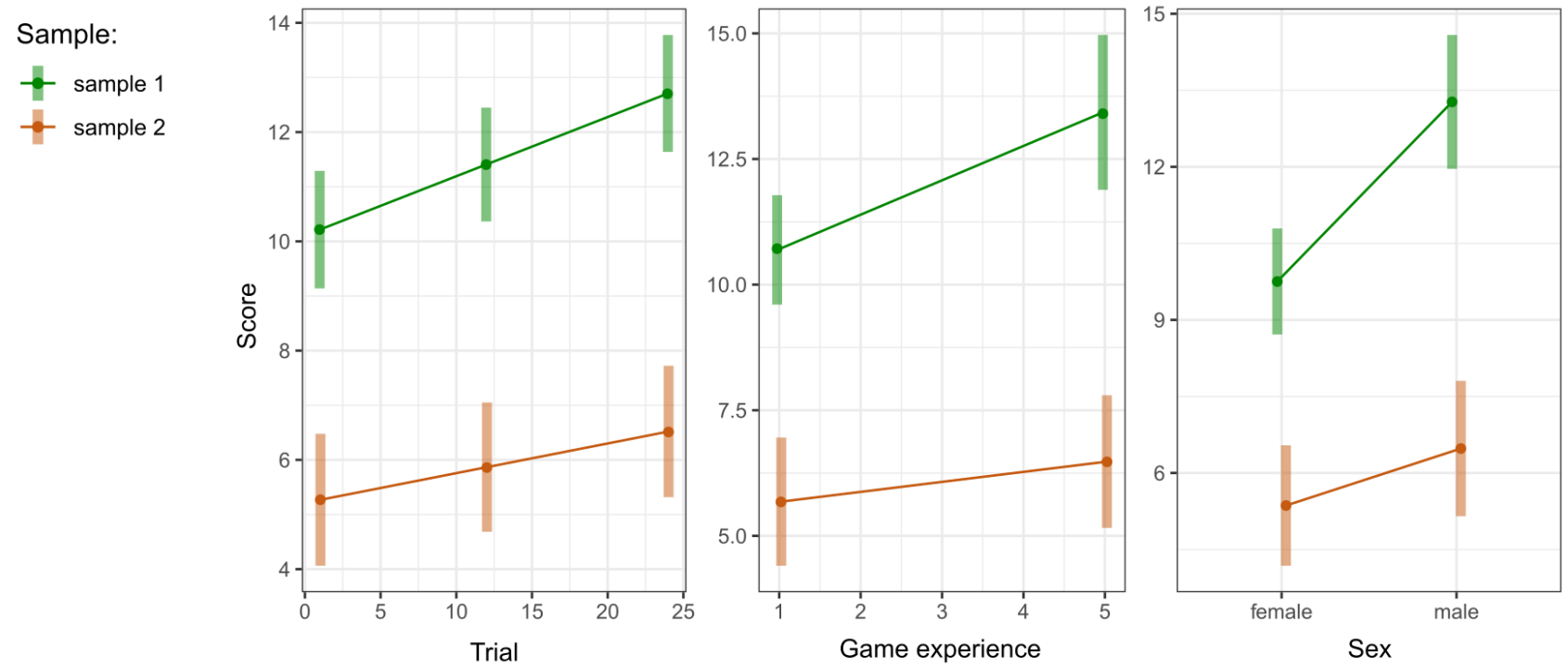

Panel B: Trait dominance*trial (Sample 2) and narcissism*trial effects (pooled analysis)
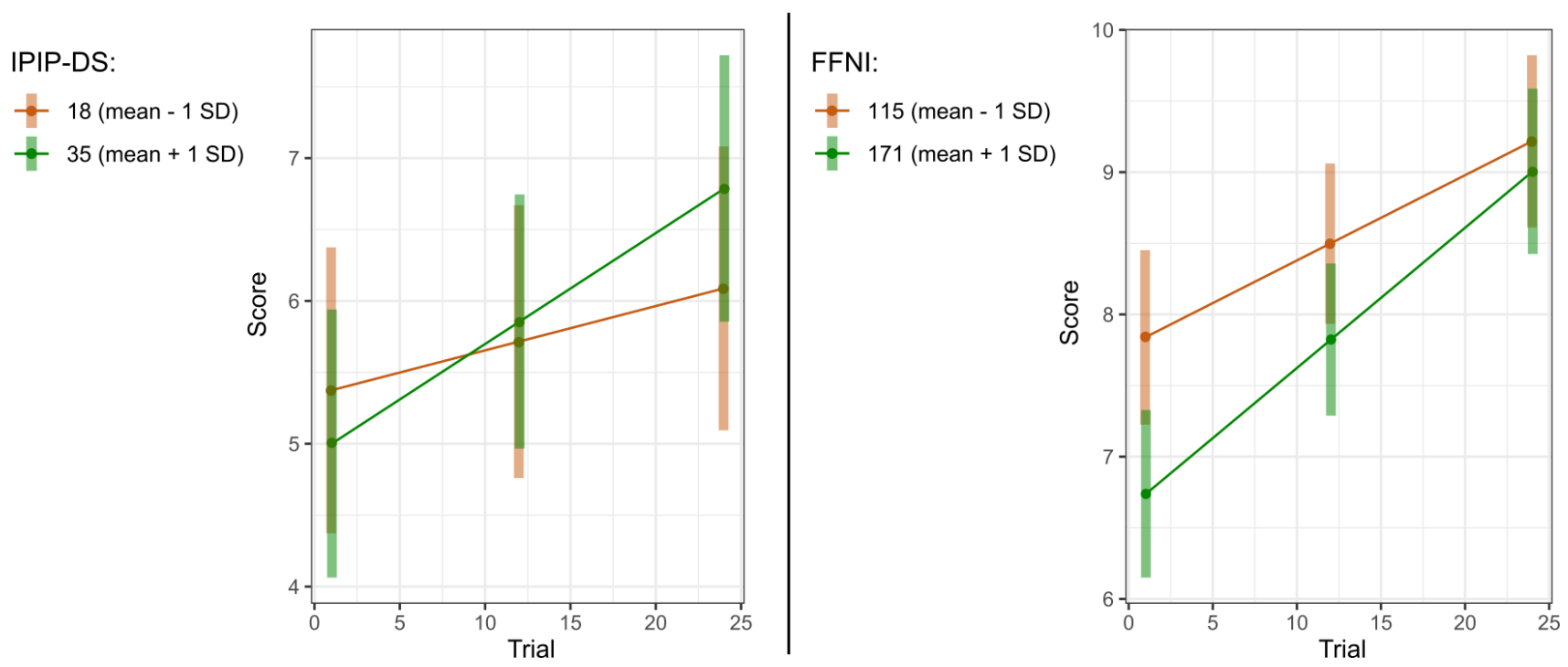

Supplemental Figure S6, Panel A: Differences between samples predicting task performance (score) in the pooled analysis. The direction of effects were similar but differences in performance with respect to trial (time on task), game experience and sex were larger in Sample 1. Panel B: Trait dominance ${ }^{\star}$ trial and narcissism ${ }^{\star} t r i a l$ interactions predicting task performance. Trait dominance and narcissism further enhanced the improvement rate of task performance. Points indicate estimates and vertical bars $95 \%$ confidence intervals. 


\section{(c) Correlations with participants' self-reported motivations and impressions}

A1. To what extent did your actions influence the outcome of the game?

A2. On average, how fair did your opponents play?

A3. How much did you enjoy playing?

A4. How well do you think you played?

M1. I wanted to perform as well as I possibly could.
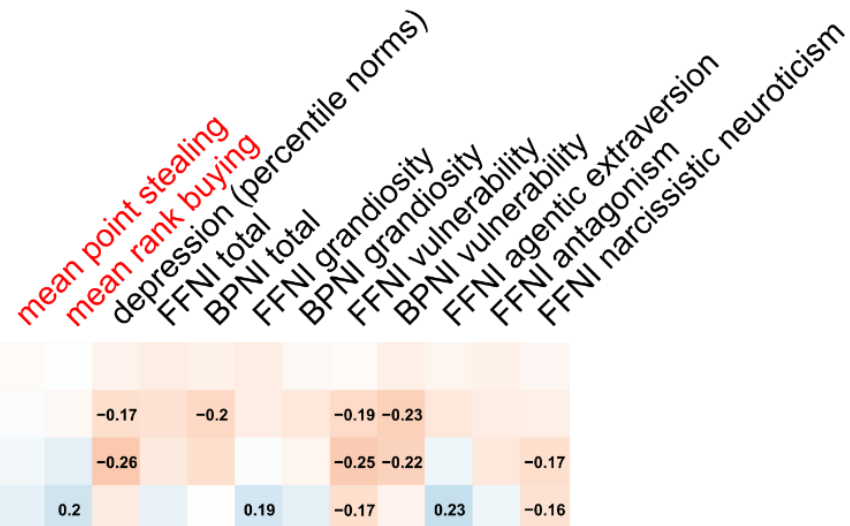

M2. Maximizing my personal record of apples eaten was important.

M3. I wanted to perform better than everyone else.

M4. I did not want to perform more poorly than everyone else.

M5. Attaining the highest rank among all the competitors was important.

M6. I wanted to take revenge on people who defeated me.

M7. I did not want to perform more poorly than I possibly could.

M8. I wanted to ensure that I win.

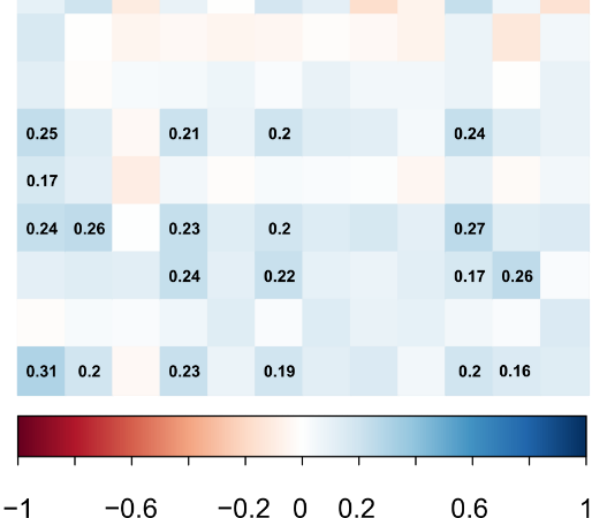

Supplemental Figure S7: Spearman correlations of mean point stealing and rank buying and psychometric measures with participants' self-reported feedback in the pooled analysis. Numbers indicate coefficients of significant correlations $(p<.05)$. Questions A1 to A4 (in blue) investigated participants' impressions about the task and were answered on an analog scale from 1 (not at all) to 10 (absolutely). Questions M1 to M8 (in black) explored participants' motivations throughout the competition on a five-point Likert scale going from 1 (strongly disagree) to 5 (strongly agree). Participants encountered the eight $\mathrm{M}$ questions and then the four A questions at the very end of the task, as these questions were built in the tournament's interface. See main text for a description of findings. Legend: FFNI, Five-Factor Narcissism Inventory; BPNI, Brief Pathological Narcissism Inventory. 